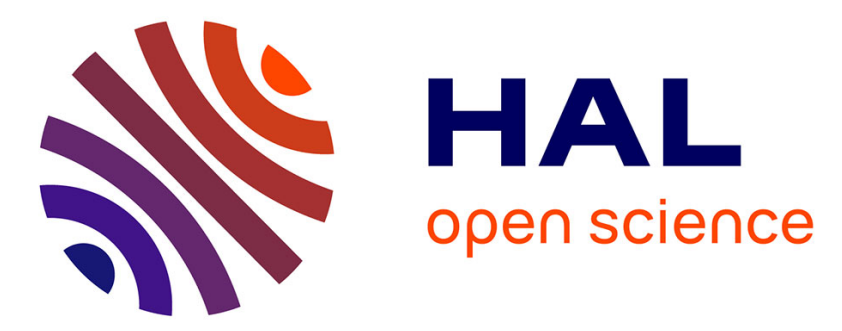

\title{
Approaches to investigate delamination and interfacial toughness in coated systems: an overview
}

\author{
Jinju Chen, Sj Bull
}

\section{To cite this version:}

Jinju Chen, Sj Bull. Approaches to investigate delamination and interfacial toughness in coated systems: an overview. Journal of Physics D: Applied Physics, 2011, 44 (3), pp.34001. 10.1088/00223727/44/3/034001 . hal-00588673

\section{HAL Id: hal-00588673 https://hal.science/hal-00588673}

Submitted on 26 Apr 2011

HAL is a multi-disciplinary open access archive for the deposit and dissemination of scientific research documents, whether they are published or not. The documents may come from teaching and research institutions in France or abroad, or from public or private research centers.
L'archive ouverte pluridisciplinaire HAL, est destinée au dépôt et à la diffusion de documents scientifiques de niveau recherche, publiés ou non, émanant des établissements d'enseignement et de recherche français ou étrangers, des laboratoires publics ou privés. 


\title{
Approaches to investigate delamination and interfacial toughness in coated systems: an overview
}

\author{
Jinju Chen $^{1^{*}}$ and SJ Bull ${ }^{2}$ \\ ${ }^{1}$ School of Engineering \& Materials Science, Queen Mary, University of London, Mile End \\ Road, London, E1 4NS, UK. \\ ${ }^{2}$ School of Chemical Engineering and Advanced Materials, Newcastle University, Merz Court, \\ Newcastle upon Tyne, NE1 7RU, UK.
}

*Corresponding author: v.chen@ qmul.ac.uk, Jinju.chen82@gmail.com

Tel: +44 (0)20 7882 7620; Fax: +44 (0)20 89831007

\begin{abstract}
The fundamental property which often dictates the performance of a coating is its adhesion to the substrate and thus there are many techniques to measure adhesion. The choice of methods is dependent on many factors such as mechanical properties of the coating and substrate, the interface properties, the microstructure of the coating/substrate system, residual stress, coating thickness and the intended application. Most tests aim to introduce a stable interfacial crack and make it propagate under controlled conditions and model this process to determine adhesion. The corresponding models are either stress analysis based or energy-based. With the advent of miniature systems and very thin functional coatings, there is a need for characterization of adhesion at small length scales and some specific tests have been developed which are not appropriate for thicker coatings. Among these, indentation and scratch methods have the widest range of applicability but it is necessary to analyze the failure mechanisms before choosing an appropriate model to extract adhesion parameters. This paper reviews the main quantitative adhesion tests for coatings and highlights the tests which can be used to assess submicron coatings and thin films. The paper also highlights the modelling and analysis methods necessary to extract reliable adhesion properties illustrating this with examples for submicron coatings on silicon and architectural glass.
\end{abstract}

Key words: Interface, Adhesion, Fracture, Coatings

\section{Introduction}

Adhesion is critical for almost all coating industries. Adhesion at an interface can be attributed to mechanical interlocking, chemical bonding, physical adsorption, or electrostatic forces. Many qualitative methods are used to determine the critical conditions for interfacial failure but, in many cases, a quantitative assessment of the adhesion is required for device design (e.g. for MEMS). Adhesion failure is often considered as a cracking event which can be described by an interfacial toughness parameter which, together with the mechanical properties of the coating and substrate, can be used to predict the onset and rate of propagation of failure. Under certain circumstances, adhesion also gives an indication of possible defects at the interface which may be correlated to other physical or electrical properties.

There is no universal technique or analysis approach to determine the interfacial toughness. For a given experimental set-up, different mechanisms of interfacial failure may occur for different coated systems or test methods and, therefore, different models are required. According to Mittal [1], the measured adhesion can be affected by test-specific factors and residual stress. 
Thus, without careful calibration between tests, including calibration of the associated analysis techniques, making comparisons between data obtained in different ways for different systems is dangerous. Also, factors that are ignored in models originally proposed for specific coated systems may be vital in other coated systems. It is not always clear which is the most appropriate test to select and the best way to analyse the test data. A very comprehensive overview given by Volinsky et al [2] was focused on the superlayer, superlayer indentation and four-point bending on the layered structure of micromechanical systems (MEMS). In this paper, we briefly review a larger range of adhesion tests and then focus on those which can be used for submicron coatings on brittle (ceramic) substrates. Some guidance for the selection of an appropriate adhesion test is also given. The techniques and models discussed here are mainly for coated systems with limited time dependent deformation. In cases where low modulus coatings show appreciable viscoelastic behaviour many of the approaches outlined here may be invalid.

\section{Definition of Adhesion and Delamination}

According to the ASTM definition (D907-70), adhesion is "the state in which two surfaces are held together by interfacial forces which may consist of valence forces or interlocking forces, or both". These forces can be Van der Waals forces, electrostatic forces or chemical bonding across the coating/substrate interface. Delamination is the phenomenon that a layer (fibre) separates from the substrate or matrix in composite materials. It can be driven by mechanical or thermal stress, shock waves, corrosion, electrostatic forces etc. It can be detected by indirect techniques such as acoustic emission or reflectivity, but is best directly observed by microscopy (light, electron, atomic force, acoustic, etc).

The true work of separation of the interface (also called the thermodynamic work of adhesion) is the amount of energy required to create new surfaces from the bonded materials.

$$
W_{A B}=\gamma_{A}+\gamma_{B}-\gamma_{A B}
$$

where $\gamma_{A}$ and $\gamma_{B}$ are the specific surface free energies of $A$ and $B$ and $\gamma_{A B}$ is the specific interfacial free energy. This is an intrinsic property that depends on the type of bonding at the interface. The true work of adhesion can be determined by contact angle measurements [3-7] and atomistic simulations [8] . Contamination can affect the true work of adhesion [7, 9]. Practical measurements of adhesion also include a contribution due to the effects of residual stress but may also include measurement-specific factors which make it problematic to compare the adhesion results obtained with different test methods unless these are well understood.

Even if such factors can be compensated for there are usually other energy dissipation mechanisms associated with the forming new surfaces. Thus, the so-called practical work of separation, critical strain energy release rate is given by [10]:

$$
\mathrm{G}_{\mathrm{int}}=-\frac{\partial U}{\partial A}
$$

where $U$ is the stored elastic energy released and $A$ is the area of the interfacial crack. An interfacial toughness, $\mathrm{K}_{\mathrm{int}}$, is related to this via $K_{\mathrm{int}}=\sqrt{E_{\mathrm{int}} G_{\mathrm{int}}}$ where $\mathrm{E}_{\mathrm{int}}$ is a representative Young's modulus for the coating/substrate system.

Prior to evaluation of interfacial toughness, it is necessary to distinguish the different interfacial failure mechanisms. The general failure modes that may generate adhesive failure in coated systems are outlined in the following 


\section{Coating failure induced interfacial failure:}

(a) Median/radial cracks propagate to the interface and deflect $[11,12]$

(b) A periodic array of cracks growing through the film may divert to the interface [13]

\section{Failure starts at the interface:}

(c) Crack initiates at the interface and propagates along the interface, or extends into coating or substrate; no buckling occurs

(d) After initial defect formation, the high compressive residual stress leads to buckling [14], [15], [16]

\section{Substrate failure induced interfacial failure:}

(e) A substrate crack may occur at or close to the interface, and divert along it to cause interfacial failure.

The different types of interface failure are summarized in Fig.1.

Interfacial failure is controlled by two main factors, the interfacial toughness, as outlined above, and the distribution of interfacial defects. The stress, $\sigma$, necessary to cause failure depends on both of these; from a simple fracture mechanics approach considering a well-developed interfacial defect of radius, $c$, the interfacial toughness, $K_{i}$ is given by

$$
K_{i}=a \sigma \sqrt{\pi c}
$$

Where the parameter $a$ is geometric constant which is usually $\sim 1$ for circular defects.

\section{Coating}

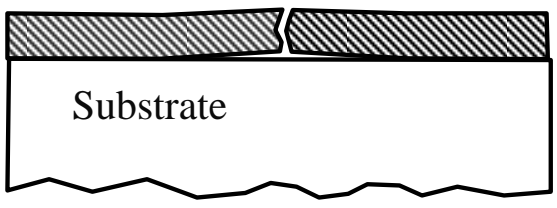

(a)

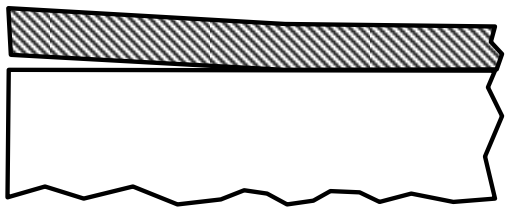

(c)

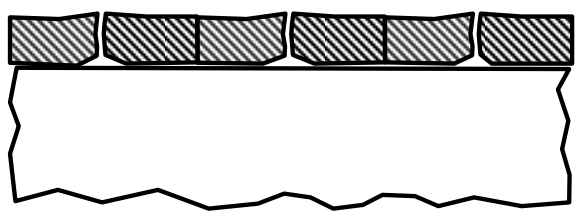

(b)

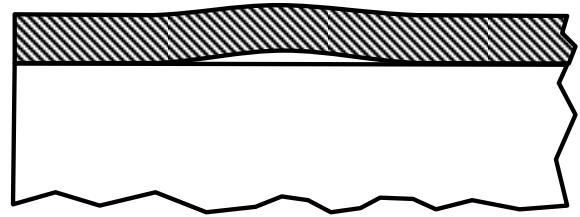

(d)

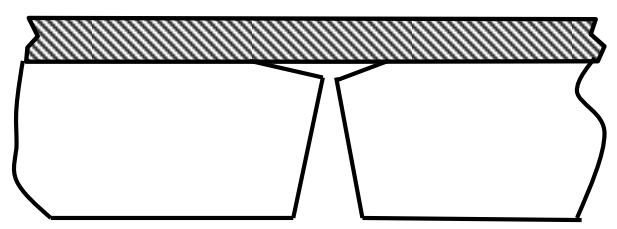

(e)

Fig. 1. Schematic of different failure modes in coated systems. (a) radial / median crack in the coating deflects to interface to cause delamiantion; (b) multiple cracks in the film (such as picture-frame cracks) divert to interface to cause delamination; (c) delamination resulting from an edge flaw at the interface; (d) compressive stress inbuckling in the film (e) a crack in the substrate divert to the interface to cause delamination. 
Different modes of failure needs to be identified (Figure 2). In the case of a thin film on a substrate a mixture of these failure modes can be observed, depending on test conditions. This mode mixity is characterised in terms of a phase angle, $\varphi$, where pure mode I (see Fig. 2a) has an angle of $0^{\circ}$ and pure mode II (see Fiog. 2b) is $90^{\circ}$. In most cases the lowest toughness is recorded for mode I fracture when coating and substrate have the same stiffness but will increase with phase angle and the degree of modulus mismatch.

(a)

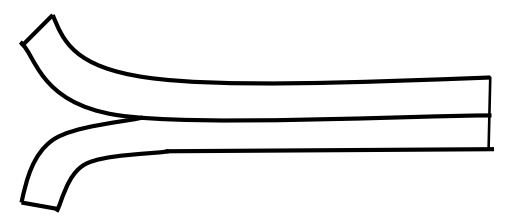

Fig. 2. Schematic of (a) mode I failure and (b) mode II failure.

For a mixed mode failure the interfacial toughness is given by[17],

$$
\begin{aligned}
& K=K_{1}+i K_{2}=\frac{p}{\sqrt{2}}\left(\frac{P}{\sqrt{t}}-i \frac{M}{t^{3 / 2}}\right) t^{i \varepsilon} e^{i \varepsilon} \\
& p=\sqrt{(1-\alpha) /\left(1-\beta^{2}\right)}
\end{aligned}
$$

The phase angle $\varphi$ is given by,

$$
\varphi=\tan ^{-1}\left(\frac{P t \sin \omega-2 \sqrt{3} M \cos \omega}{P t \cos \omega+2 \sqrt{3} M \sin \omega}\right)
$$

Where $M$ is the bending moment caused by load $P, \omega$ is the real angular function, and the bimaterial constant $\varepsilon$,

$$
\varepsilon=\frac{1}{2 \pi} \ln \left(\frac{1-\beta}{1+\beta}\right)
$$

For non-zero values of $\varepsilon$ the stress fields oscillate because the asymptotic solutions for stress fields yield a compex solution equation (4a). The stress fields oscillate for nonzero values of $\varepsilon$, therefore, the ratio $K_{\mathrm{I}} / K_{\mathrm{II}}$ does not correspond directly to the ratio $\sigma_{y y} / \tau_{x y}$.

For plane strain, the Dundurs parameters, $\alpha$ and $\beta$, which account for the differences in elastic response of the coating and substrate are originally given by $[18,19]$,

$$
\begin{aligned}
& \alpha=\frac{\left(\mu_{1} / \mu_{2}\right)\left(1-v_{2}\right)-\left(1-v_{1}\right)}{\left(\mu_{1} / \mu_{2}\right)\left(1-v_{2}\right)+\left(1-v_{1}\right)} \\
& \beta=\frac{\left(\mu_{1} / \mu_{2}\right)\left(1-2 v_{2}\right)-\left(1-2 v_{1}\right)}{2\left(\mu_{1} / \mu_{2}\right)\left(1-v_{2}\right)+\left(1-v_{1}\right)}
\end{aligned}
$$


Where $\mu_{1}$ and $\mu_{2}$ are shear moduli, $v_{1}$ and $v_{2}$ Poisson's ratios for materials 1 and 2 .

These two parameters can be further simplified as [20]

$$
\begin{aligned}
& \alpha=\frac{\bar{E}_{f}-\bar{E}_{s}}{\bar{E}_{f}+\bar{E}_{s}} \\
& \beta=\frac{1}{4}\left[\frac{\bar{E}_{f}\left(1-v_{f}\right)\left(1-2 v_{s}\right)-\bar{E}_{s}\left(1-v_{s}\right)\left(1-2 v_{f}\right)}{\left(\bar{E}_{f}+\bar{E}_{s}\right)\left(1-v_{s}\right)\left(1-v_{f}\right)}\right]
\end{aligned}
$$

where $\bar{E}_{f}$ and $\bar{E}_{s}$ are the plain strain moduli and $v_{\mathrm{s}}$ and $v_{\mathrm{f}}$ are the Poisson's ratios of coating and substrate respectively. The parameter $\alpha$ denotes the mismatch in extensional stiffness between the two bonded materials whereas $\beta$ indicates the mismatch in volumetric stiffness. If the elastic properties of coating and substrate are the same then $\alpha=\beta=0$ and the bimaterial constant $\varepsilon=0$. As the modulus mismatch increases both $\alpha$ and $\beta$ (and hence $\varepsilon$ ) diverge from zero.

\section{Techniques to assess interfacial toughness}

In this part, we will review the methods to determine the interfacial toughness by inducing the various types of failure as shown in Fig.1. These include pull-off and peel tests(tape tests [21]), scratch testing [22-25], four point bend tests [26, 27], stressed overlayers [28-30], indentation tests [24, 31-33], laser spallation tests [34, 35], double cantilever beam tests[36, 37] and microcantilever deflection etc. We will start with brief review of the most common techniques before going into more detail about the indentation and scratch tests which are often the only available tests for thin hard coatings.

\subsection{Brief review of the techniques for adhesion assessment}

Pull-off methods: These methods include the tape peel test or the tangential lap shear technique (e.g. [38], [39]). The tape test uses a pressure sensitive adhesive tape to pull off the coating to determine the peel force per unit tape width. It is quite easy to apply, but the main disadvantage is that it can be only applied to thick and rather weakly bonded coatings. Alternatively, one may bond rods to the coating and substrate by a structural adhesive and then perform a tensile test to pull off the coating (see Fig. 3.), which can measure tougher interfaces. However, the perfect alignment necessary to ensure uniform loading across the interface is difficult to achieve in particular for small samples. The mixture of tensile and shear stress during the test also leads to difficulty in the interpretation of the results. When the coating becomes thinner, diffusion of the adhesive through the coating to the interface may be important. This test measures the strength of the interface rather than interfacial toughness. The test is limited by the strengths of available adhesives to an interfacial strength of less than $~ 50 \mathrm{MPa}$. For some coating/substrate systems it is possible to braze or weld the rods to the coating to increase this maximum strength but with penalty that considerable residual stresses are introduced and the coating/substrate system may be damaged by the bonding process.

A variant of the tensile test which is very useful for brittle coatings on very ductile or compliant substrates involves loading the coating/substrate system into the jaws of a conventional mechanical test frame and stretching so that the substrate extends beyond the fracture strain of 
the coating (Fig 3b). In this case an array of parallel tensile through-thickness cracks is formed in the brittle coating by stress transfer from the substrate. At higher deformations the Poisson's contraction induces compressive stresses in the parallel-sided segments of coating bounded by these tensile cracks and this can lead to delamination of the coating. This is a very common failure modes for metal-coated polymer samples [40].

(a)
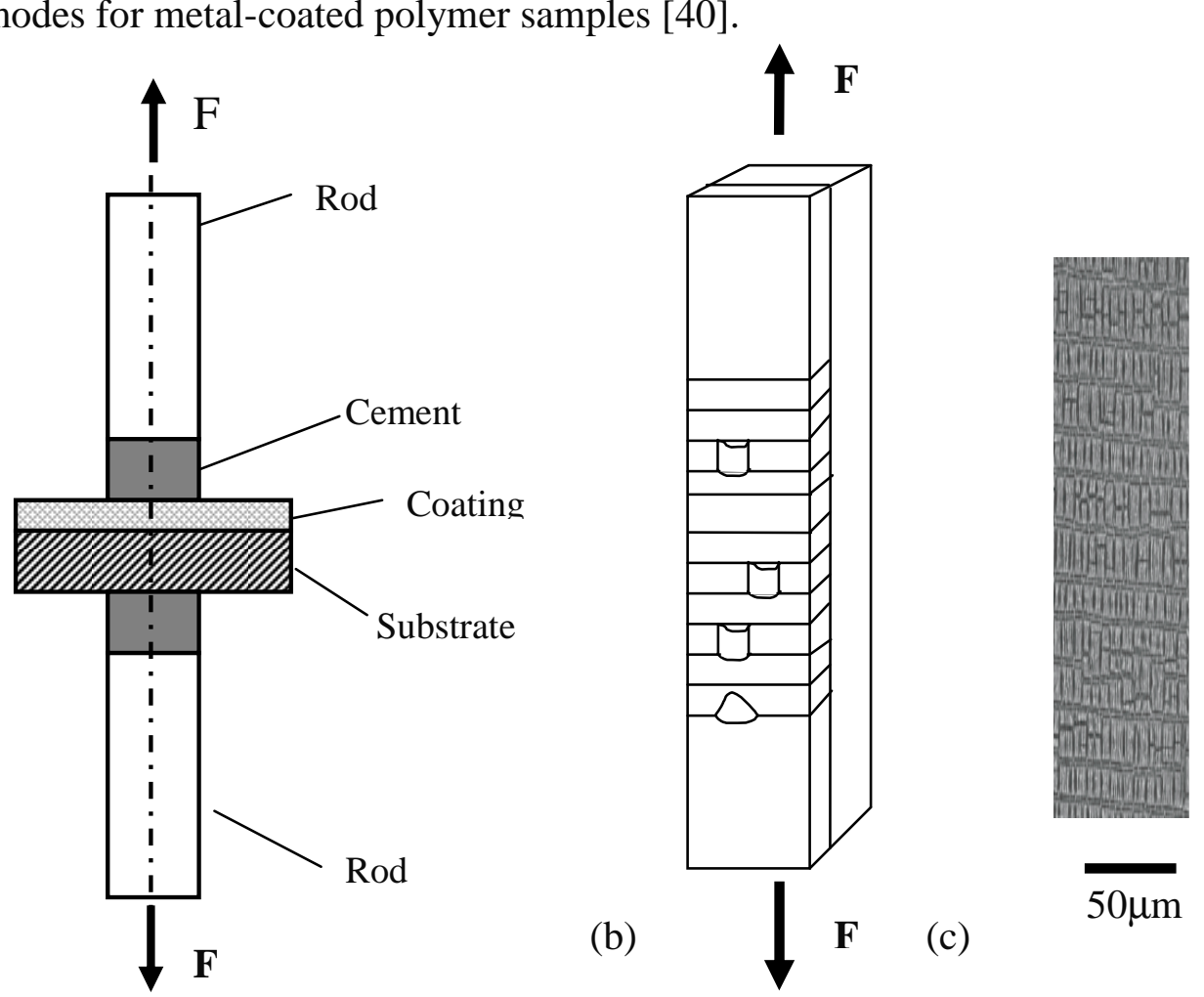

Fig. 3. Schematic of (a) Pull-off adhesion test and (b) tensile test of brittle coating/ ductile substrate system. Through-thickness cracking perpendicular to the loading axis is followed by adhesive buckling failure between the cracks. (c) Light micrograph of adhesion failure in copper/polyimide after the test in (b).

Stressed overlayer test: This requires depositing a thick superlayer on the top of the film of interest so that it increases the apparent film thickness and the total residual stress in the combined coating without altering the tested interface ([2],[28]). This makes it easier to debond the interface. This method is almost always applied to metal-ceramic systems.
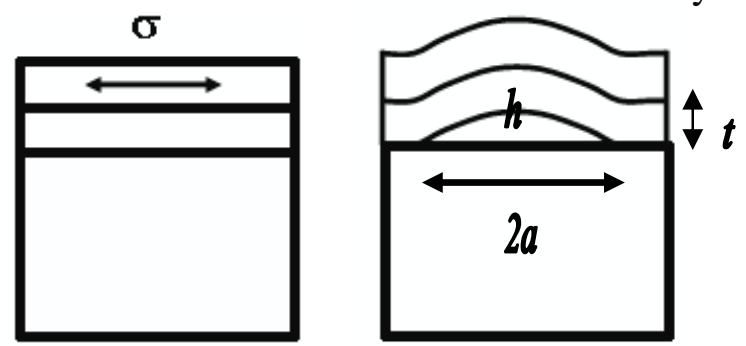

Fig.4. Schematic of residual stress induced failure at the tested interface by a highly stressed overlayer on top of the tested coating.

In this case, the interfacial toughness can be directly estimated based on simple stress analysis. Hutchinson and Suo considered the contribution to the energy release rate $G_{\text {int }}$ for the interface by the critical buckling stress $\sigma_{\mathrm{c}}$ and driving stress $\sigma_{\mathrm{r}}$ of the film (i.e. the residual stress in the coating), thus [17], 


$$
\begin{aligned}
G_{\mathrm{int}} & =\left[\frac{\left(1-v_{f}^{2}\right) t}{2 E_{f}}\right]\left(\sigma_{r}-\sigma_{c}\right)\left(\sigma_{r}+3 \sigma_{c}\right) \\
\sigma_{c} & =\frac{k t^{2} E_{f}}{12\left(1-v_{f}^{2}\right) a^{2}}
\end{aligned}
$$

For example, when a 400nm highly stressed indium doped tin oxide (ITO) coating ( $3 \mathrm{GPa}$ compressive stress) was deposited on the top of an $\mathrm{Ag} / \mathrm{ZnO}$ bilayer on glass it caused spontaneous delamination at the $\mathrm{ZnO} / \mathrm{Ag}$ interface as shown in Fig. 5. This gives a strain energy release rate of $2.7 \pm 0.1 \mathrm{~J} / \mathrm{m}^{2}$ for the $\mathrm{Ag} / \mathrm{ZnO}$ interface based on equation (5).

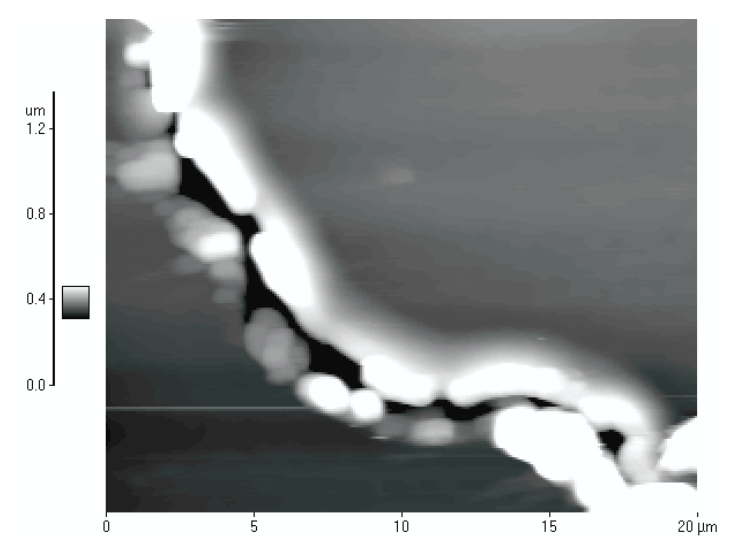

Fig.5. Delamination of $\mathrm{ZnO} / \mathrm{Ag}$ interface due to a highly stressed 400nm ITO overlayer on top.

A more advanced superlayer test which requires more sample preparation and experimental setup was described by [2]. Although an accurate adhesion strength can be measured by this technique, it requires tedious tests to alter the thickness of and stress within the superlayer until controlled delamination occurs. Furthermore, the interface between the overlayer and the test coating should be stronger than the interface between the test coating and substrate, which is not always possible to achieve.

Bending test: This is usually used for metal-ceramic system where through- thickness fracture in the coating diverts to the interface to cause interfacial failure as shown in Fig.6 [e.g. [41], [42]]. This method usually requires a relatively big sample with a thick coating which is robust enough to remain free-standing after detachment and it cannot account for pre-existing residual stress in the coating [2]. This method may not work well for ceramic-ceramic systems since it is more likely to cause catastrophic failure of the whole coated system due to the brittle nature of the coating and substrate. However, it is widely used to assess the adhesion of thick ceramic coatings on metallic substrates (e.g. [42]). 


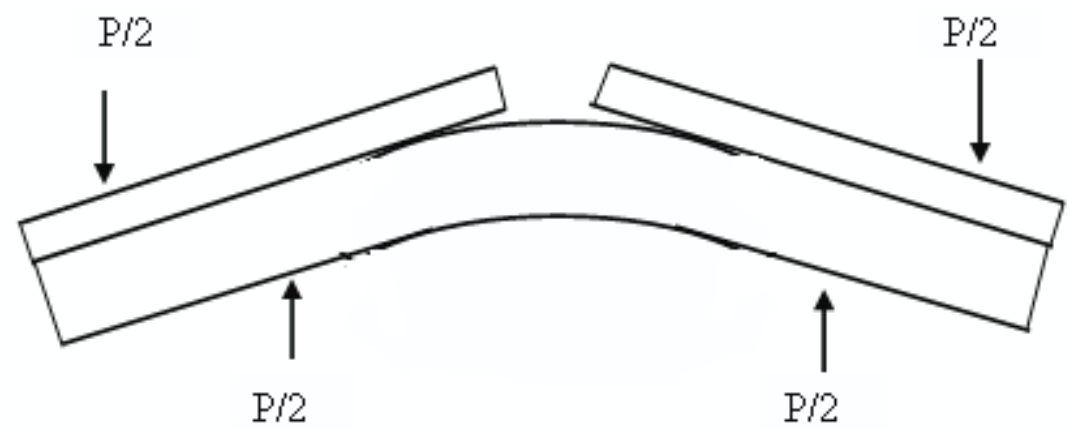

Point A

Point B

Fig.6 Schematic of the four point bending test for adhesion measurement.

The four point bending test is preferred since the region between the central rollers is subject to pure bending and the analysis of interfacial is relatively simple provided there is no plastic deformation. Thus

$G=\frac{21\left(1-v^{2}\right) P^{2} L^{2}}{16 E b^{2} t^{3}}$

where $t$ is coating thickness, $b$ is the width of the plate, $L$ is the distance between Point A and C .

Sometimes, three point bend tests have also been used to measure adhesion [43]. Indentation (or nanoindentation) techniques can also be combined with bending tests to measure adhesion; in such tests the indentation test is used to produce an interfacial defect of a known size and this is propagated by the bending stresses applied. In most cases it is the reliable production of the starter crack which limits the application of the technique since discontinuous crack growth of a non planar crack front is common.

Blister test: In a blister test, pressure is applied on the free-standing film to cause film debond from the substrate as shown in Fig.7. This requires etching the substrate to obtain a free-standing thin film window and the application of pressure on one side to cause deflection of the film. It is relatively straight-forward method to analyse the delamination stresses.

The strain energy release rate is given by [44]

$$
\begin{gathered}
G=P \delta \frac{k_{v}}{\pi}\left(\frac{4+5 \phi}{4+4 \phi}\right) \\
\phi=\frac{{ }^{c}{ }_{2} E_{f}^{\prime}}{{ }_{c}{ }_{1} \sigma_{0}}\left(\frac{\delta}{r}\right)^{2}
\end{gathered}
$$

Where $E^{\prime}$ is the biaxial modulus of the tested film, $\sigma_{0}$ is the initial tensile stress in the film, $\mathrm{r}$ is the bulge radius, $\delta$ is the blister height, $c_{1}$ and $c_{2}$ are geometry related parameters, $k_{v}$ is blister shape-dependent parameter and (1.62 and 1.94 for a circular or square window, respectively[44]). This analysis assumes that the bulge dimensions are controlled by the film properties alone which may not be the case for compliant substrate materials. 


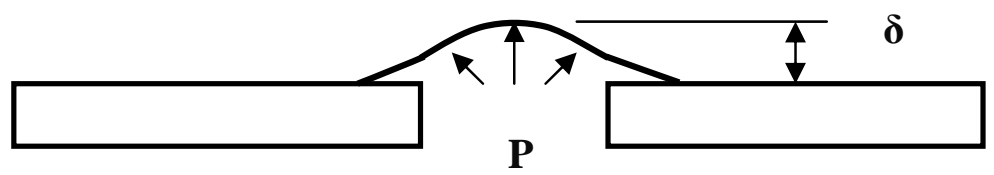

Fig. 7. Schematic of Blister test.

The etching may lead to contamination of the interface especially for thin ceramic films on ceramic substrates during processing of the free-standing films. It was also argued that it may not work for thin films $(<2 \mu \mathrm{m})$ due to possible wrinkling effects [45]. As commented in [2], it is difficult to interpret the results the when crack does not propagate uniformly along the perimeter of the blister.

Double Cantilever Beam test: In the original test (Fig. 8), the coating is bonded between two rigid plates. The energy release rate can be determined by measuring the fracture load, precrack length and the height of the specimen ([2], [46]). The advantage is that this method leads to almost pure mode I failure which makes it easier to analyze. It works well for relatively thick coatings; however, it is difficult to apply to thin films because it is hard to create a suitable precrack (as for other bend tests) and the bonding of the rigid plates may damage the interfaces to be tested. However, recently this approach has been successfully applied to very thin multilayer oxide coatings on glass where the thickness of each individual layer is below 50nm [36, 37, 47].

The energy release rate determined by this sort of adhesion test is given by [48],

$$
G=\frac{3 E t^{3} \delta^{2}}{16(L+0.6 t)^{4}}
$$

Where $E$ is Young's Modulus and $t$ is the thickness of the glass beam, and $\delta$ and $L$ are the crack opening and crack length respectively.

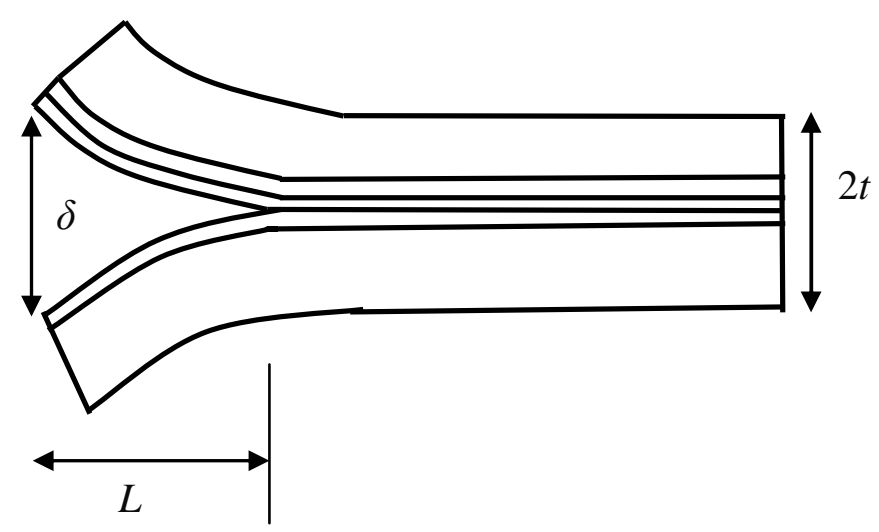

Fig. 8 Schematic of the DCB test for the adhesion measurement[47].

This method yields reasonable results for multilayer coatings on glass as shown in Table 1 .

Table 1 Interfacial toughness determined by DCB tests [37, 47]

\begin{tabular}{|l|l|}
\hline Multilayer & Strain Energy release rate $\left(\mathrm{J} / \mathrm{m}^{2}\right)$ \\
\hline $\mathrm{Si}_{3} \mathrm{~N}_{4} / \mathrm{TiO}_{2} / \mathrm{Ag} / / \mathrm{TiO}_{2} /$ glass & $0.75+/-0.01$ \\
\hline $\mathrm{Si}_{3} \mathrm{~N}_{4} / \mathrm{ZnO} / \mathrm{Ag} / / \mathrm{ZnO} /$ glass & $1.0+/-0.02$ \\
\hline $\mathrm{Si}_{3} \mathrm{~N}_{4} / \mathrm{ZnO} / \mathrm{Ag} / / \mathrm{ZnO} / \mathrm{Si}_{3} \mathrm{~N}_{4} /$ glass & $2.1+/-0.04$ \\
\hline $\mathrm{Si}_{3} \mathrm{~N}_{4} / \mathrm{ZnO} / \mathrm{Ag} / / \mathrm{SnO}_{2} /$ glass & \\
\hline
\end{tabular}


Shockwave tests (laser spallation): In this group of tests delamination is produced by a shockwave [49]. The fracture dissipated energy may come from impact of erosive particles or from an impinging laser pulse. The main problem is that the process of creating the shockwave may influence the surface in particular for thin films. It is also difficult to couple the laser radiation to the surface if the coating or substrate is transparent at the laser wavelength.

Microcantilever deflection tests: With the aid of focused ion beam (FIB), the microcantilever can be fabricated. Nanoindentation can be then utilized to perform cantilever deflection experiments[50] as shown in Fig.9.

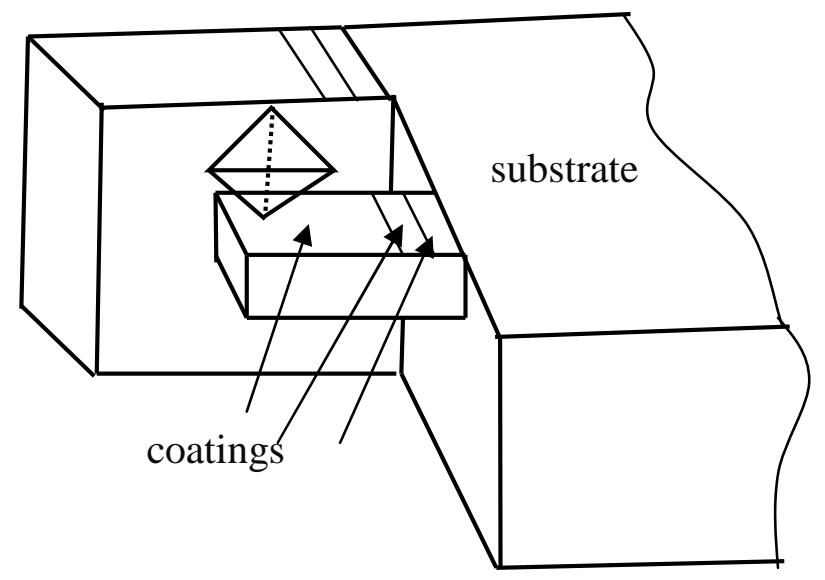

Fig. 9 Schematic of the microcantilever deflection test.

The energy release rate can be determined based on fracture mechanics [51], assuming that the bending stresses may be determined by a simple beam theory.

$$
\begin{aligned}
K & =1.12 \sigma \sqrt{\pi a} \\
\sigma & =\frac{6 P l}{W t^{2}}
\end{aligned}
$$

where $P$ is the maximum applied load and $W$ is the width of the cantilever beam. This technique has been successfully applied to determine the interfacial toughness of $\mathrm{SiO}_{2} /$ metal coatings on a $\mathrm{Si}(100)$ substrate which yields an energy release rate of 0.7 to $4.8 \mathrm{~J} / \mathrm{m}^{2}$ [50] This method is very sensitive to the initial defect size and the sample preparation is tedious.

Scratch test: This test involves dragging a stylus across the surface of the coating with a stepwise or continuously increasing normal load until an adhesion related failure occurs at what is termed the critical load, $L_{c}$. This critical load is often used to compare different materials but this is only valid if the same failure mode occurs. This is a simple way to estimate adhesion, which is usually regarded as semi-quantitative because it can be affected by various extrinsic (instrument-specific) factors such as scratch speed and loading rate and intrinsic (coating/substrate system) parameters such as coating thickness, substrate hardness and surface roughness which influence the results. It is very useful for qualitative assessment of hard coatings on a softer substrate (e.g.[52-57]).

For a hard coating with relatively small thickness $(<5 \mu \mathrm{m})$, buckling is the most common failure mode which is usually caused by the compressive stress generated ahead of the moving indenter (see Fig.10). Unlike for the case of spontaneous buckling, where a pre-existing interfacial defect is required, the shear stresses associated with plastic deformation in the substrate tend to create a suitable defect with dimensions comparable to scratch width, and buckling failure is widely 
observed. However, since plastic deformation is responsible for the initial defect the critical load is dependent on substrate hardness and comparisons between coatings on different substrates are difficult to make reliably. For a much thicker coating, through thickness cracking is preferred to occur during scratch testing which can lead to wedge spallation (see Fig.11). This is because the bending stiffness of the coating has increased. When such wedge spallation occurs comparisons between different coatings are more meaningful and reliable quantification is possible [57]. More details about the models to determine the interfacial toughness will be discussed in the following section.

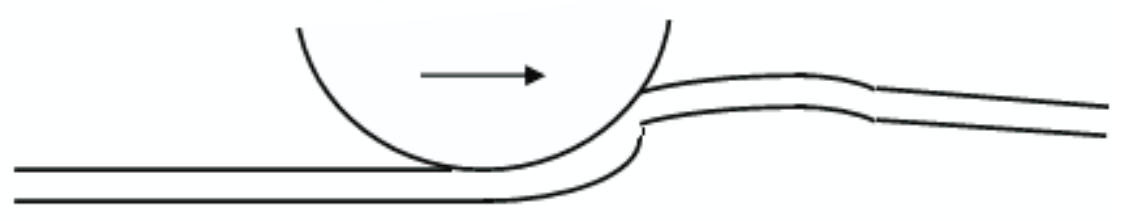

(a)

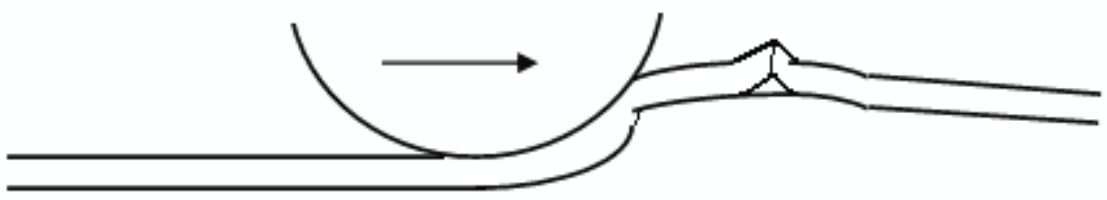

(b)

Fig. 10. Buckling failure mode in thin coatings during scratch testing : (a ) pile-up ahead of the moving indenter; (b) interfacial failure resulting in buckling. After [57].

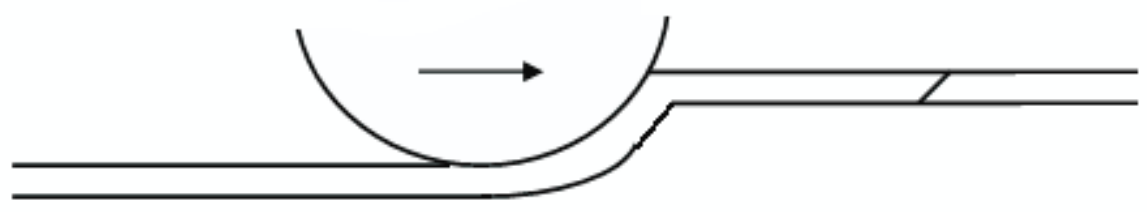

( a)

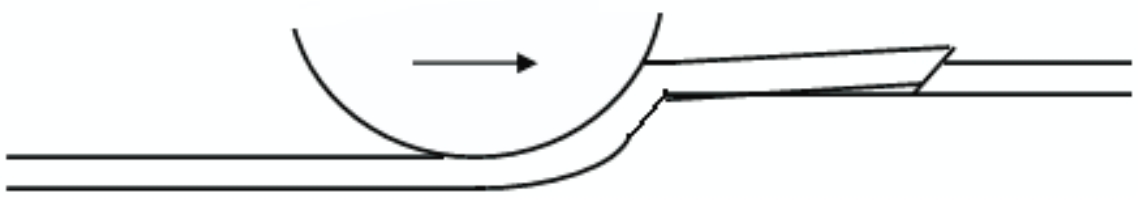

(b)

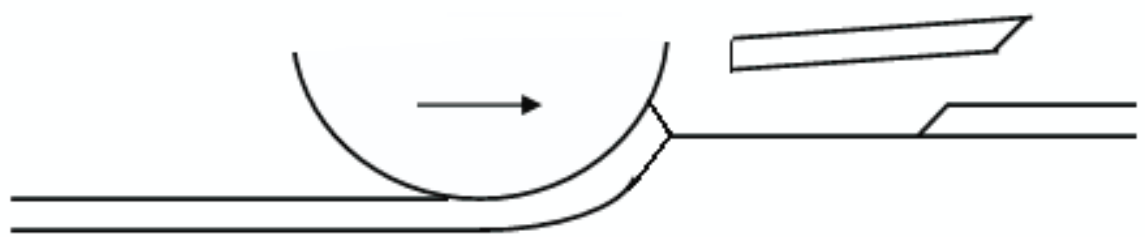

(c)

Fig. 11. Wedge spallation failure mode in thick coatings during scratch testing: (a) wedge crack is generated some distance ahead of the moving indenter; (b) the coating is driven up the wedge opening an interfacial crack (c) through thickness cracking close to indenter leads to spallation. After [57]

If the coating is soft, significant plastic deformation may be associated with delamiantion. When the interfacial shear stress is bigger than the shear strength of the softer component, the scratch test is not very useful. In such case, stripping or flaking may occur if adhesion is very poor but often there is little to see but a plastic groove after the test is done. For thin soft films, the 
nanoscratch can be very useful. Due to the relatively small size, it is difficult to relocate the scratch track under off-line SEM or AFM. Therefore, an in-situ scanning probe microscopy can be very useful to image the nanoscratch induced delamination (e.g. Fig. 12). The initiation of delamination can also be correlated to the sudden change of friction coefficient.

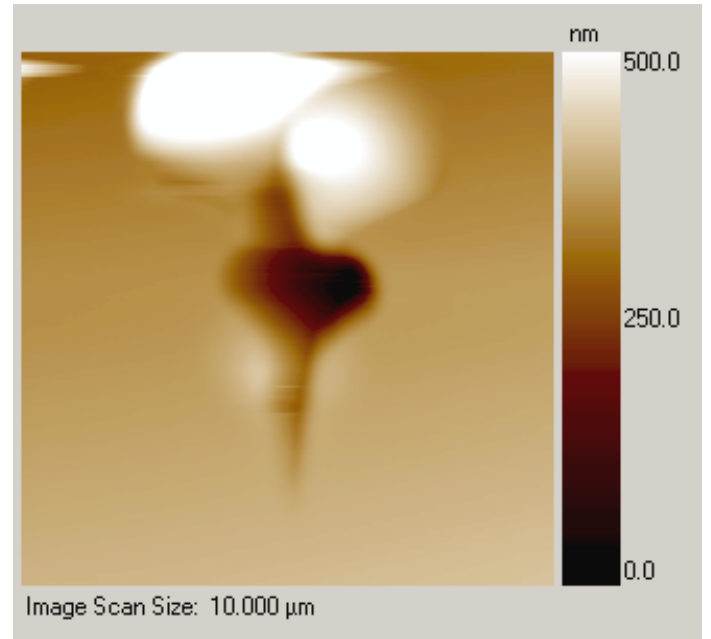

(a)

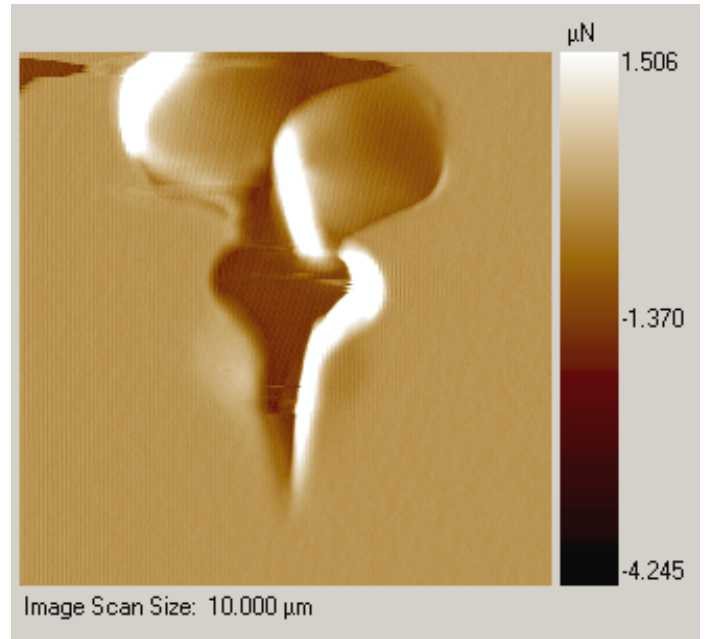

(b)

Fig. 12. (a) Topographical and (b) gradient in-situ images of a scratch (with a ramping load up to $2 \mathrm{mN}$ ) induced delamination in a multilayered low- $k$ polymer coating on silicon substrate.

Indentation: For thin films, nanoindentation is a very effective technique to measure the mechanical properties of the coatings such as Young's modulus, hardness, and fracture toughness and interfacial toughness [[24], [58], [59]]. For a soft coating (usually not brittle), when the indenter penetration reaches a critical value, the high compressive stress in the coating may result in double buckling as depicted in Fig.13a (if the interfacial toughness is not too high and there is an appropriate interfacial defect). If the crack length does not reach its critical buckling length on each side of indenter, single buckling may occur during the unloading cycle (Fig.13b). The initial double buckling may change into single buckling during the unloading because the constraint of the coating underneath the indenter is removed. It is also possible that the double buckling remains even after removing the indenter.

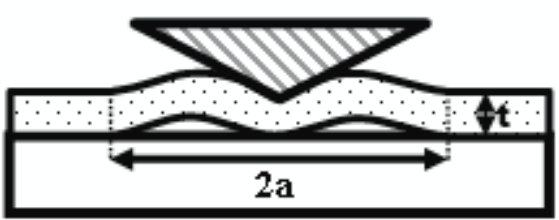

Double buckling

(a)

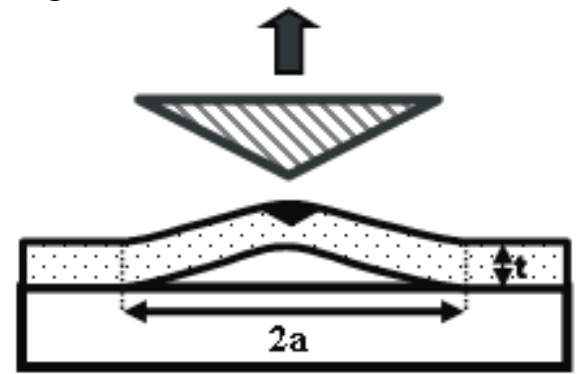

Single buckling

(b)

Fig.13. Schematic of (a) double buckling forms during loading and (b) single buckling during unloading for a relatively soft coating on hard substrate. 

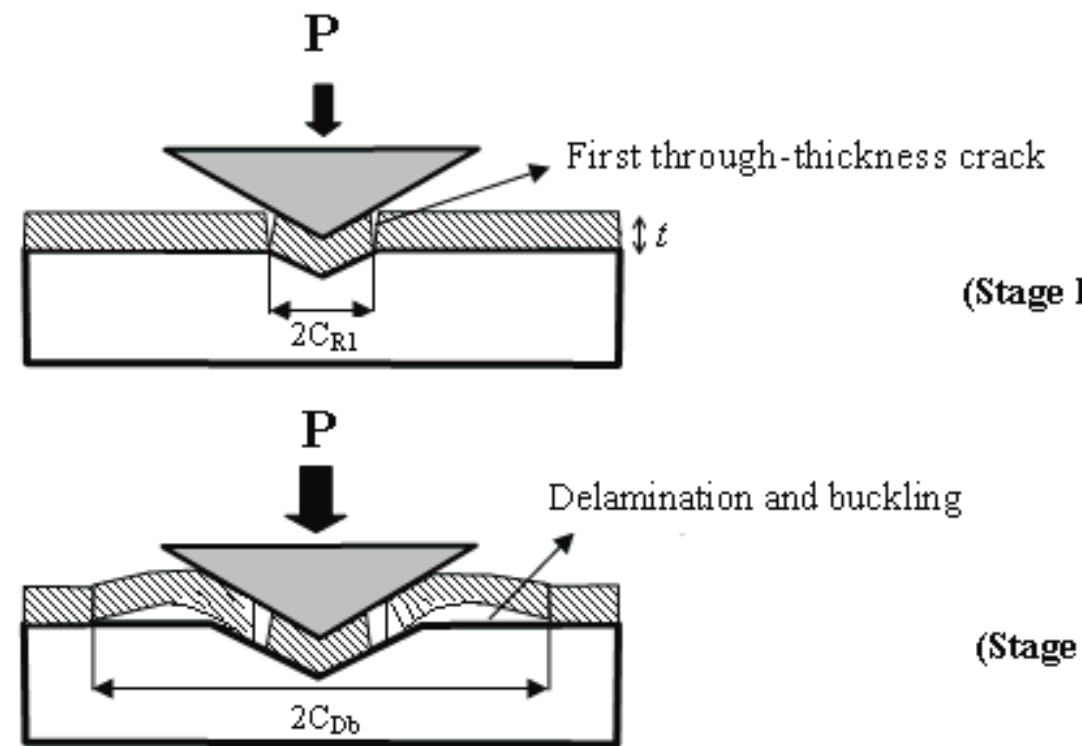

(Stage II)

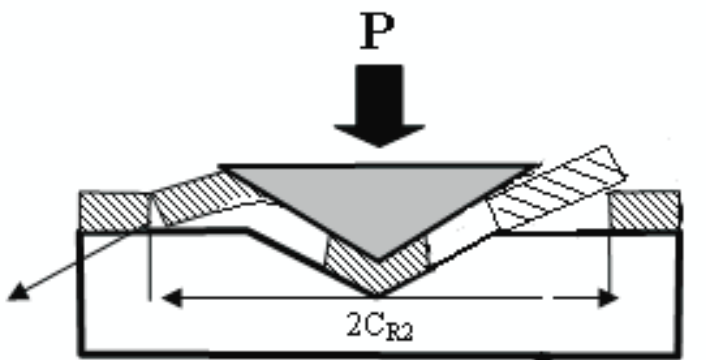

Partial spalling

(Stage III)

Secondary through-thickness crack

Fig. 14. Schematic of the different stages in nanoindentation fracture for a brittle coating on a hard substrate. Modification is made after [60].

However, for brittle coatings the failure mechanisms can be more complex. A schematic of the different stages in nanoindentation fracture for a brittle coating on a hard substrate is depicted in Fig.14. Considering that the buckling interfacial failure is more likely than the shear induced delaminaiton when the coating is relatively tough compared to the interface, some modification was made to the originally proposed indentation induced failure mechanism by [60]. The fracture evolution in a typical brittle coating on a hard substrate can be described in the following. Stage I : a ring, picture frame or radial crack may occur depending on the coating/substrate system and indenter geometry; Stage II: with the increase of the load, the crack opening increases and the coating delaminates and buckles; Stage III: secondary throughthickness cracks form and coating spallation (either partial or full) may occur depending on the flaw size distribution at the interface. A typical example for this was depicted in Fig.15.

(a)

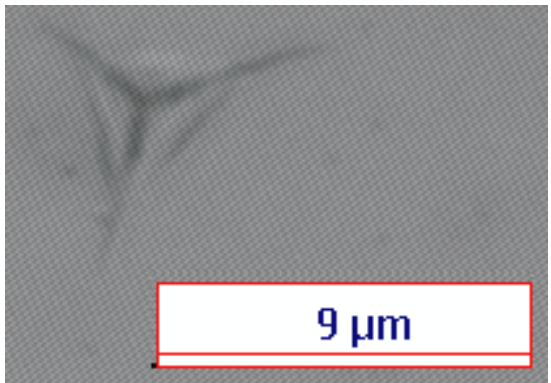


(b)

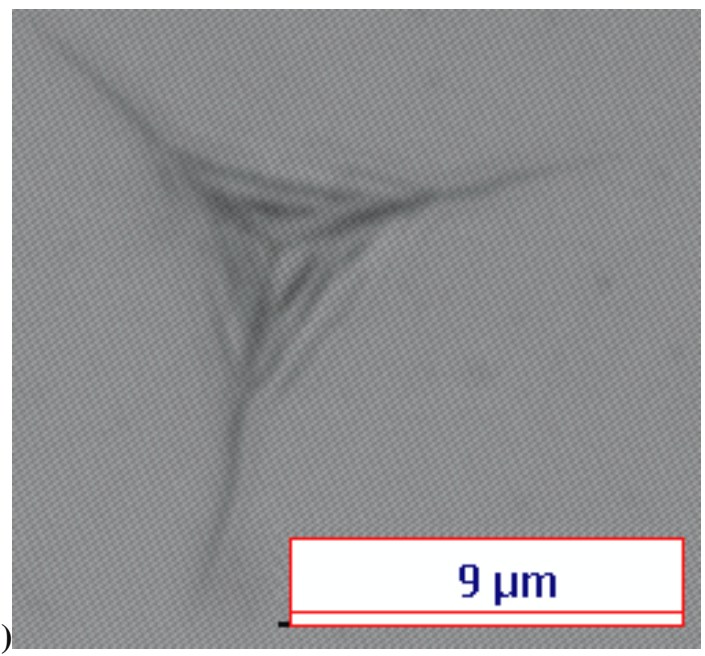

(c)

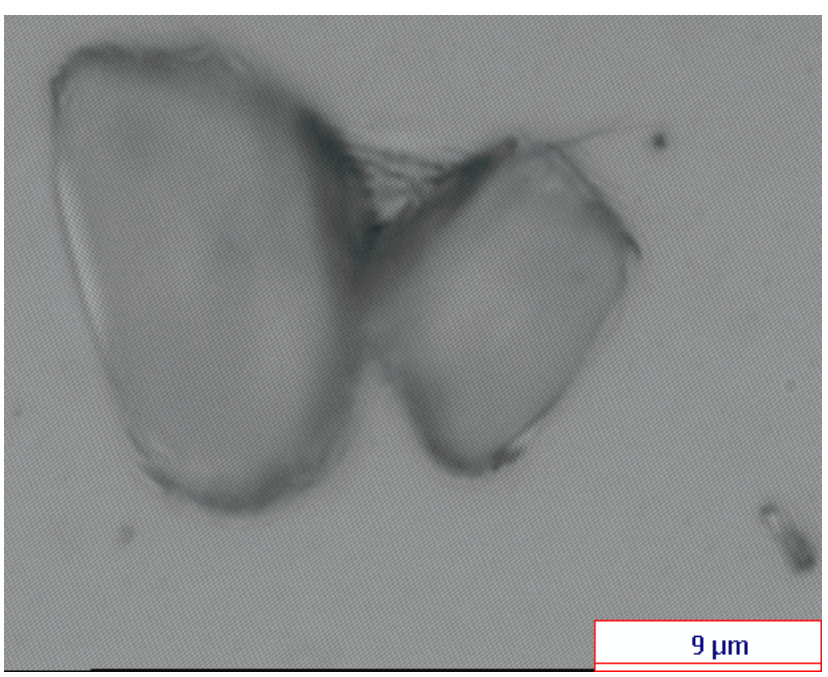

Fig. 15. Reflect light micrographs corresponding to indentations made in 200nm SiC on $\mathrm{Si}$ (111) by a Berkovich indenter at (a) $100 \mathrm{mN}$, (b) $250 \mathrm{mN}$ and (c) $500 \mathrm{mN}$. Where the crack evolution is represented in Fig.14.

\subsection{Critical review on adhesion assessment by indentation techniques}

Most work to date deals with a crack which initiates at and propagates along the interface. However, even in this case, the detailed failure mechanism needs to be examined before choosing an appropriate model. Therefore, it is necessary to identify the delamination mechanism: (a) compressive stress induced delamiantion during loading (b) tensile stress triggered delamination during unloading. Generally speaking, if the interface is very weak compared to the coating and substrate, the coating/substrate interface tends to fail during loading as shown in Fig 16a. If the interface is relatively strong or the whole coated system tends to dissipate the indentation energy by plastic deformation, the coating/substrate interface will only fail during unloading (if at all) rather than loading as shown in Fig. 16b. In the case of Fig.16a, the coating tends to buckle and this can cause chipping if the coating is brittle as shown in Fig.17a. In this case, the crack tip of the delamination crack extends outside the contact zone. In the case of Fig. 16b, the delamination is normally confined to the contact region as shown in Fig.17b.

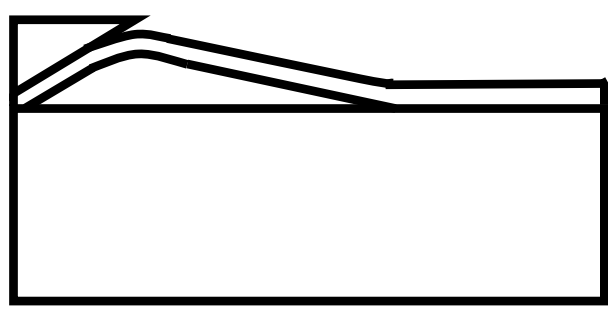

(a)

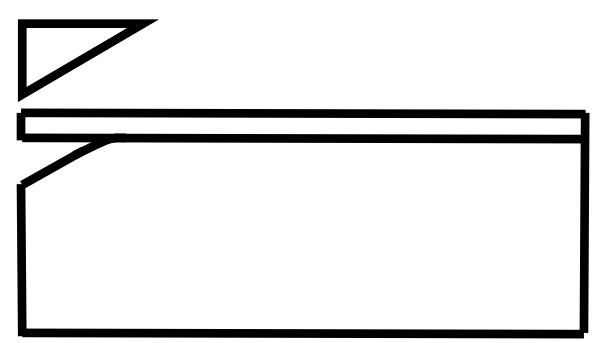

(b)

Fig.16. Schematic of indentation induced delamination during (a) loading and (b) unloading. 


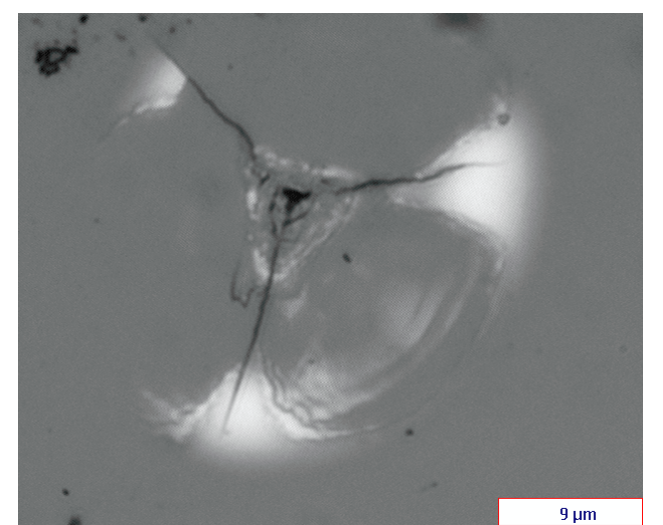

(a)

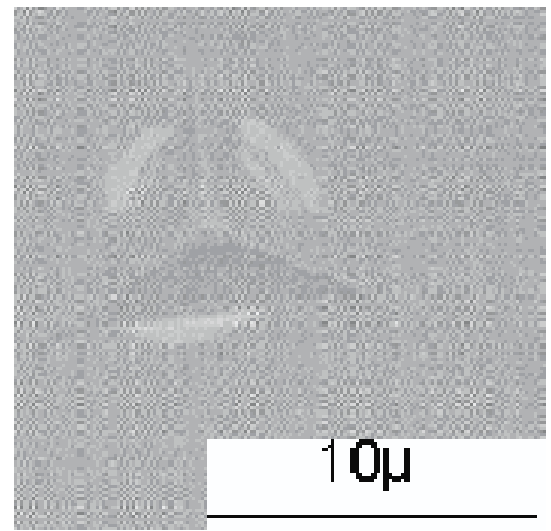

Fig.17 (a) Delamination generated during loading for a $1 \mu \mathrm{m} \mathrm{SiC}$ on $\mathrm{Si}$ (100) and (b) delamination generated during unloading for a multilayer solar control coating (with the total thickness less than 200nm) on glass .

\subsubsection{Delamintion formed during loading}

\subsubsection{Models based on normal indentation techniques}

The theoretical approach by He et al [61] analyses the kinking of a crack at and out of the interface between two dissimilar elastic solids, and this forms the basis for the indentation analysis of other workers.

Marshall et al developed a model to determine the energy release rate by delamination from comparisons between the unbuckled and buckled coating [32]. The strain energy release rate is,

$G_{\mathrm{int}}=\frac{\frac{1}{2} t \sigma_{i}^{2}\left(1-v_{f}^{2}\right)+t(1-\alpha)\left(1-v_{f}\right)\left(\sigma_{r}^{2}-\left(\sigma_{i}-\sigma_{B}\right)^{2}\right)}{E_{f}}$

where

$\alpha=1-\frac{1}{1+0.902\left(1-v_{f}\right)}$

And the indentation stress $\sigma_{i}$ is,

$$
\sigma_{i}=\frac{V_{i} E_{f}}{2 \pi\left(1-v_{f}\right) t a^{2}}
$$

where $V_{i}$ is the indentation volume (which can be estimated either based on the loaddisplacement curve and indenter geometry or the profile of the indentation impression) and $a$ is the crack length. The subscript $f$ denotes the properties of the film, $\sigma_{i}$ and $\sigma_{B}$ are the indentation stress and buckling stress, respectively. The parameter $\alpha$ is the slope of the buckling load versus the edge displacement which is 0.38 for materials with Poisson's ratio of $1 / 3$. In the case of nonbuckling fracture $(\alpha=1)$, delamination is only driven by the indentation stress and the residual stress does not make contribution. The term $\alpha$ is defined as zero if the film does not buckle.

Assuming the crack tip is far from the indenter, then 
$\sigma_{B}=\frac{k t^{2} E_{f}}{12\left(1-v_{f}^{2}\right) a^{2}}$

Where $a$ is crack length, $k$ is a boundary condition-dependent constant, $k=42.67$ for a double blister and $k=14.68$ for a single blister.

This model was further developed by Hutchinson and Suo [14], such that

$$
\begin{aligned}
& G_{\mathrm{int}}=\frac{t(1-\alpha)\left(1-v_{f}\right)\left(\sigma^{2}-\sigma_{C}{ }^{2}\right)}{E_{f}} \\
& \sigma=\sigma_{r}+\frac{V_{i} E_{f}}{2 \pi\left(1-v_{f}\right) t a^{2}}
\end{aligned}
$$

Where $\sigma_{r}$ is the residual stress. These models all assume no strain energy dissipated for possible cracks in the substrate.

Recently, these models have been further extended by [62],

In the case of non-buckling,

$$
G_{\text {int }}=\frac{\left(1-v_{c}\right) t \sigma_{i}^{2}}{E_{c}},
$$

In the case of buckling,

$$
G_{\mathrm{int}}=\frac{\left(1-v_{c}\right) t}{E_{c}}\left(4 \sigma_{i} \sigma_{B}-3 \sigma_{B}^{2}\right)
$$

Where the critical buckling stress is given by,

$$
\sigma_{B}=\frac{\pi^{2}}{24} Y\left(\frac{E_{c}}{1-v_{c}}\right)\left(\frac{t}{r}\right)^{2}
$$

where $Y$ is a dimensionless constant which was found to be 1.488 for a circular buckles [63] , $t$ is the coating thickness and $r$ is the radius of circular crack caused by a conical tip.

The indentation induced stress is given by,

$$
\sigma_{i}=E_{c}^{\prime} \frac{V_{i}}{V_{c}}
$$

It is assumed that the film around the tip is incompressible and thus the volume is conservative. The plastic indentation volume $V_{i}$ is given by,

$$
V_{i}=\frac{\pi}{3} \delta_{p}^{3} \tan ^{2} \theta
$$

Where $\theta$ is the semi-included tip angle and $\delta_{p}$ is the plastic depth. 
The volume of delaminated material is,

$V_{c}=r^{2} t \pi$

The effective modulus is given by [62],

$E_{c}^{\prime}=E_{c} \frac{1}{2\left(1-v_{c}\right)} \quad$, for conical indenter or pyramid tip

$E_{c}^{\prime}=E_{c} \frac{1}{\left(1-v_{c}^{2}\right)}$, for wedge indenter

This approach yields reasonable results for low-k dielectric films with various thicknesses on a Si substrate $[62,63]$.

For a soft coating on a rigid substrate, approaches based on contact radius at the initiation of delamination under the indenter have been proposed [64]. The following expression linking interfacial shear strength to coating hardness was given by [64],

$$
\tau_{c}=\frac{0.56 H_{c}}{K_{1}^{\prime}\left(\phi a_{c} / t\right) / \phi K_{1}\left(\phi a_{c} / t\right)+v t / a_{c} \phi^{2}}
$$

Where $H_{c}$ is the hardness of the coating, $K_{1}$ is a modified Bessel function of the second kind, $K_{1}^{\prime}$ is the derivative of the function $K_{1} ; a_{\mathrm{c}}$ is the contact radius, and

$$
\phi=[6(1-v) /(4+v)]^{1 / 2}
$$

The interfacial toughness, $K_{\text {int }}$ is then given by [65],

$$
K_{\text {int }}=\tau_{c} \sqrt{\pi c_{\text {int }}}
$$

where interfacial failure was treated as mode I failure and $c_{\text {int }}$ is the appropriate flaw size at the interface. In this way, Malzbender et al [12] obtained an average interfacial toughness of 0.18 MPam ${ }^{0.5}$ for their hybrid coatings on glass which falls into the range of results determined previously based on the work by $\mathrm{He}$ et al [61]. This indicates that this model works well, however, $c_{\text {int }}$ is not easy to accurately determine. Therefore, it may be more convenient to relate the interfacial toughness to a crack dimension that can be readily measured. It should be pointed out that the thickness $t$ of the soft coating may not be constant from point to point on the surface due to process irregularities (e.g. [66]) which can have a major effect on the scatter of results determined.

For the adhesive failure of relatively soft films with axisymmetric geometries, Rosenfeld et al [67] proposed a model which relates interfacial fracture toughness to coating hardness $H$, applied load $P$, and delamination size $c$,

$$
K_{\mathrm{int}}=\frac{0.792 H \sqrt{\left(1-v^{2}\right) t}}{\left[1+v+2(1-v) H c^{2} / P\right]}
$$

This assumes that the pressure at the interface is approximately equal to the hardness of the coating, which is reasonable for a soft coating or a sufficiently thick coating on a substrate under 
the condition that the effect of cracking on the hardness can be ignored. It is easy to use due to its concise formulation, but it tends to considerably overestimate the adhesion depending on the actual coated systems investigated. Table 2 depicts the interfacial fracture toughness for $\mathrm{CN}_{\mathrm{x}}$ coatings $(1 \mu \mathrm{m}$ thick) deposited on different samples determined by equation (14). The results are too high for these interfaces when compared to results from other tests. Overestimation was also found for sol-gel coatings with thickness of several $\mu \mathrm{ms}$ on float glass [12].

Table 2. Values of the interfacial fracture toughness for $1 \mu \mathrm{m} \mathrm{CN}_{\mathrm{x}}$ coatings deposited on different samples determined by equation (14) [68].

\begin{tabular}{|l|l|}
\hline Coated system & $\mathrm{K}_{\text {int }}, \mathrm{MPa} \sqrt{\mathrm{m}}$ \\
\hline $\mathrm{CN}_{\mathrm{x}} / \mathrm{Si}(001)$ & 5.92 \\
\hline $\mathrm{CN}_{\mathrm{x}} / \mathrm{Al}_{2} \mathrm{O}_{3}$ & 4.67 \\
\hline $\mathrm{CN}_{\mathrm{x}} / 3 \mathrm{C} \mathrm{SiC}(001)$ & 5.51 \\
\hline $\mathrm{CN}_{\mathrm{x}} / \mathrm{SiC}(111)$ & 5.58 \\
\hline
\end{tabular}

To account for this deviation, Malzbender et al [67] treated the delamination occurring between radial cracks as three separate circular clamped plates with deflection at the centre instead of the initial assumption of a clamped circular plate without deflection at centre. Thus the buckling stress and shear stress at interface can be reduced by approximately one third [61] and Malzbender et al [12] obtained reasonable results for interfacial toughness. In addition, friction between the fracture faces may also contribute overestimation of the interfacial fracture toughness especially for mode II failure [69].

All these models treat the buckling as an elastic blister which is reasonable when the crack tip is far from the plastic deformation zone; otherwise plastic deformation must be accounted for. Therefore, instead of elastic plate theory, a model of a travelling plastic hinge at the apex of the buckled coating was adopted during stress analysis was presented to assess indentation induced delamination for a ductile film on elastic substrate to deal with the problem that buckling is inside the plastic deformation zone [70]. Compared to the models based on LEFM (e.g. Marshall et al [71] and Hutchinson and Suo [17]) this travelling plastic hinge model gives very good prediction of adhesion for interfaces with intermediate toughness where the plastic deformation zone does not extend beyond the buckling height. However, it shows significant deviation from numerical simulations (see details in [70]) for both very weak and very strong interfaces.

The models discussed above are based on stress analysis, and energy based models represent the other major approach. Sometimes it is observed that there is a slope change in the plot of irreversible work during indentation $\left(W_{i r r}\right)$ against the applied load $P$ when delamination occurs [58]. The difference between the measured $W_{i r r}$ and the extrapolated $W_{i r r}$ was assumed to be the energy dissipated by delamination (see Fig.18) [58]. The presence of radial cracking prior to delamination may change the $W_{i r r}-P$ relationship. With the increase of the load, the substrate begins to play a significant contribution to the $W_{i r}-P$ behaviour. Therefore, such a model may not be as accurate as expected. For example, the method tends to significantly overestimate the interfacial toughness in [58]. To eliminate the change of apparent Young's modulus and hardness caused by cracking, delamination and substrate deformation, it was further suggested to obtain the fracture dissipated energy by extrapolating $\Delta W_{i r r}$ versus the inverse of coating thickness to infinite coating thickness. In this way, the reasonable approximation (the same order of magnitude) of interfacial toughness can be achieved [58]. However, this method requires tests at a number of loads on coatings with different thickness, which is tedious and costly and relies on the adhesion being constant for different deposition runs. It should be pointed out that actually the $W_{i r r}$ method is also only valid in the case of a feature in load-displacement curve otherwise the slope change may not be observed (e.g. [72]). 


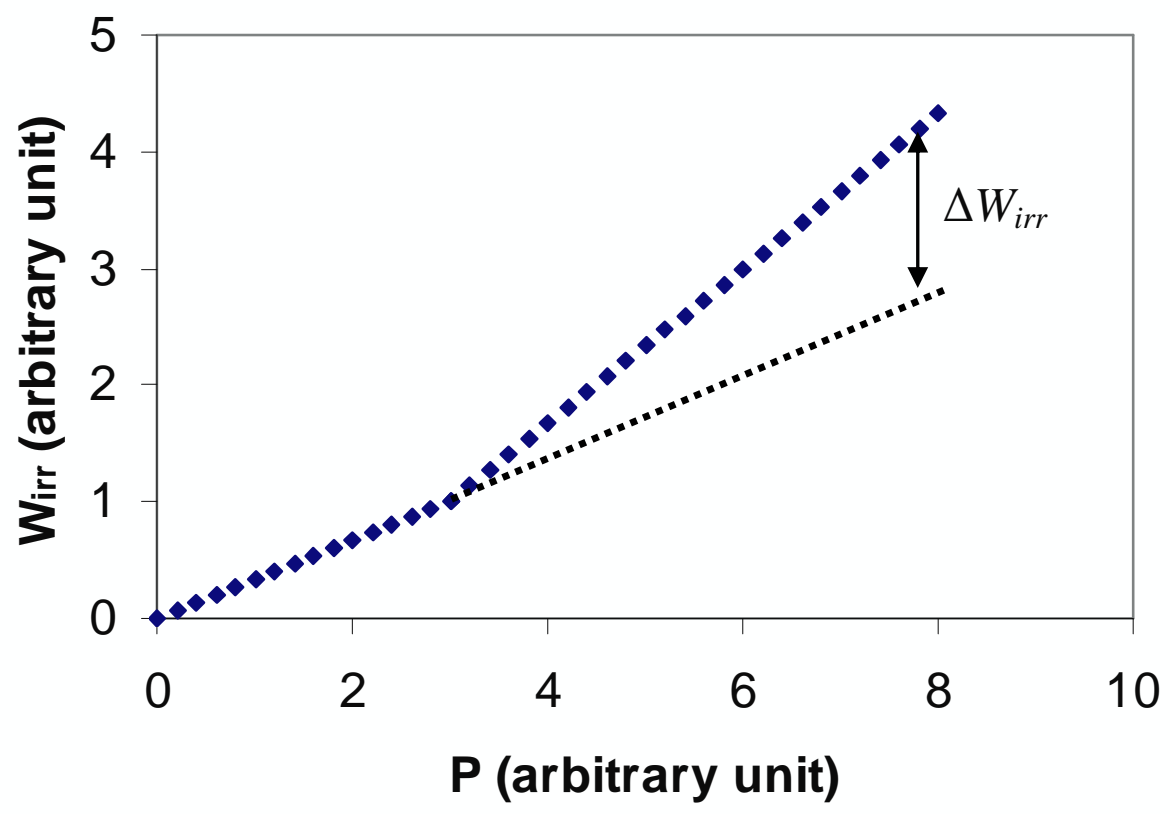

Fig.18 Schematic of the change in irreversible energy dissipated as a function of applied load after adhesion failure during indentation [58].

\subsubsection{Some special indentation techniques}

In addition to the development and improvement of the models described above, some special indentation techniques have also been proposed. For instance, testing with a special indenter such as the wedge indentation test was proposed to measure adhesion of thin metal lines (see Fig. 19) $[73,74]$,. This method is less sensitive to the measurement accuracy of crack length and it is easier to induce interfacial failure compared to the normal indentation test by conical indenters or pyramids due to its geometry. Later it was applied to a brittle coating on a ductile substrate [75] . For a brittle coating on ductile substrate, a stress analysis based model was derived based on the expanding cavity model. The schematic of the wedge delamination test is depicted in Fig. 19.

Compared to the axisymmetric indentation test, radial crack formation is not a problem in this technique because no tensile hoop stress develops in the coating [75]. The other significant advantage is that this technique is suitable for the study of relatively strong interface which may not be assessed by the normal axisymmetric indenter. But this model ignores the bending effect in the film and substrate during the indenting cycle thus causing errors especially for ductile substrates [2].

If a ductile coating adheres strongly to the substrate, the above methods will not work since no delamination will occur during normal indentation tests. For this reason, a superlayer enhanced indentation test was introduced. A highly stressed hard superlayer was deposited onto the ductile coating which causes additional stress to enhance delamination and eliminate pile-up around the indenter during indentation. By altering the residual stress in the superlayer, it is possible to measure interfacial toughness at different phase angles [76]. 


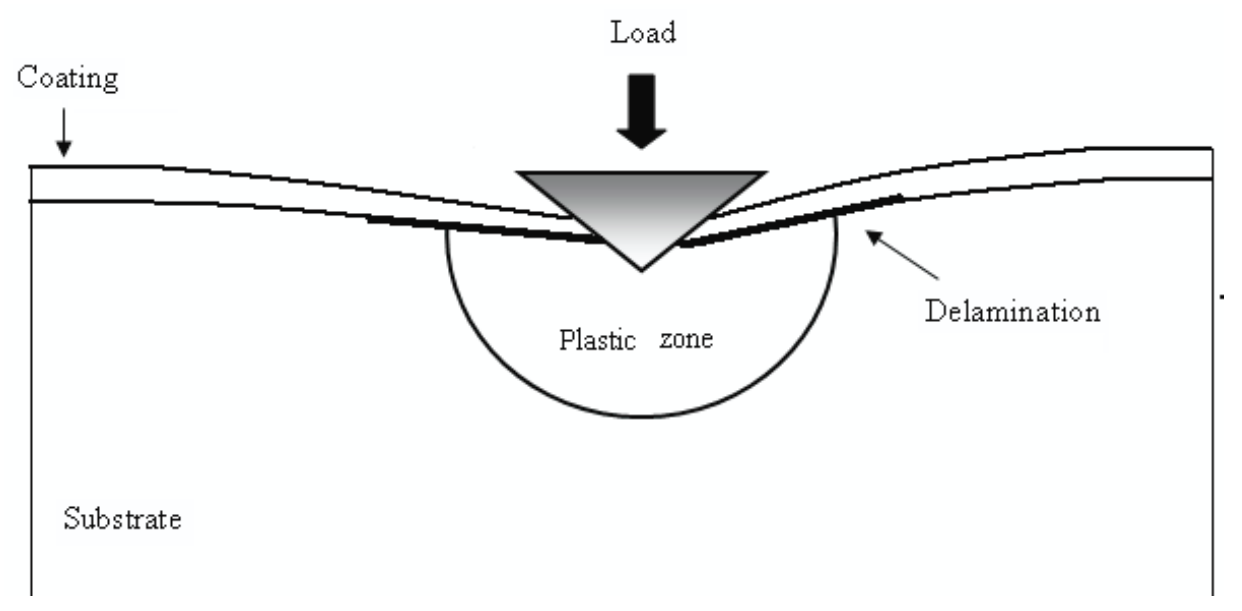

Fig.19. Schematic of the wedge delamination test.

In order to eliminate the influence resulting from plastic deformation, in particular, for a ductile coating on a much stiffer substrate, a cross-sectional indentation test was suggested [77-80]. An indentation is made in a polished cross-section in the substrate close to the film interface which then causes delamination (see Fig.20). Assuming the interface is a homogeneous material with the Young's modulus and hardness as combined parameters of coating and substrate, analogy to an equivalent bulk material is made and the interfacial toughness is given by [79],

$$
K_{\mathrm{int}}=0.015(E / H)_{\mathrm{int}}{ }^{1 / 2} P / a^{3 / 2}
$$

where $P$ and $a$ are the critical load and contact radius for the delamination at the interface, respectively.

$$
(E / H)_{\mathrm{int}}^{1 / 2}=\frac{\left(\frac{E}{H}\right)_{s}^{1 / 2}}{1+\left(\frac{H_{f}}{H_{s}}\right)^{1 / 2}}+\frac{\left(\frac{E}{H}\right)_{f}^{1 / 2}}{1+\left(\frac{H_{s}}{H_{f}}\right)^{1 / 2}}
$$
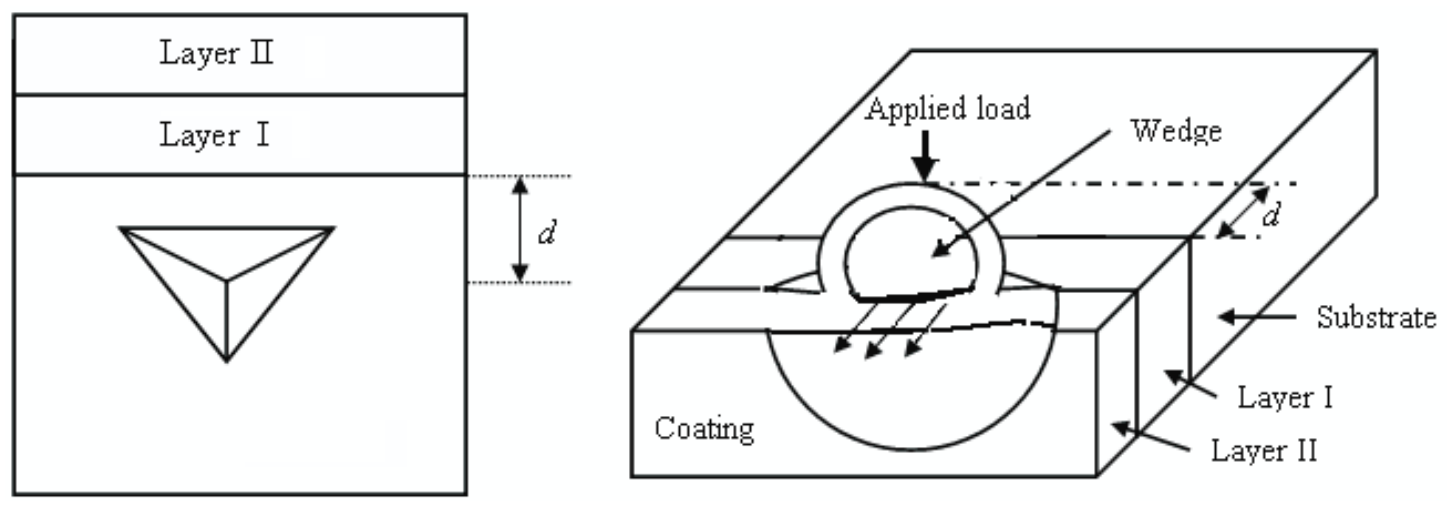

Fig.20 Schematic of the cross-section indentation test.

Where the subscripts $s, f$ and int refer to the substrate, film and interface.

Equations (15a) and (15b) provide reasonable results for very thick ceramic (hundreds of micrometers) coatings on steel. However, if the mismatch between the coating and substrate 
properties is very significant, it is not reasonable to treat the interface as an equivalent bulk material given in equation (15b).

This method was further developed by Sanchez et al [80]. Based on a plate model, the energy release rate for the interface is given by [80],

$$
\begin{gathered}
G_{\text {int }}=\frac{E t^{3} u_{0}^{2}}{12(a-b)^{4}}(1-\lambda)^{4}\left(2 F+\lambda F^{\prime}\right) \\
F(\lambda)=\frac{2 \ln \lambda+\frac{1+\lambda}{1-\lambda} \ln ^{2} \lambda}{[(1+\lambda) \ln \lambda+2(1-\lambda)]^{2}}
\end{gathered}
$$

where $a, b$ are the delamination radius and contact radius, respectively ; $u_{0}$ is the maximum film deflection, $t$ is film thickness, $\lambda=a / b$, and $F^{\prime}=d F / d \lambda$.

This method is particularly useful for a coating on a brittle substrate. The crack initiates in the brittle substrate and can propagate along the weaker interface as indicated in Fig.1e. The essence of this method is that it induces a pre-crack at the interface. The disadvantage of this method is that there are some critical parameters such as orientation of the indenter tip and the indentation position with respect to the interface for controlled delamination, which must be accurately known.

\subsubsection{Delamination induced during unloading}

If the coating/substrate interface is relatively strong but still much weaker than the coating and substrate, the coating may fail during unloading rather than loading. This is observed in both experiments [31-34] and numerical simulations [35]. For a multilayer stack, the failure mechanisms are much more complex because the multilayer stack may alter the fracture pathway. In such cases, even the nominally weak interface may not fail during loading but fail during unloading during an indentation test as observed in [16].

Little work has been done for the delamination generated when withdrawing the indenter from the tested sample. A model based on elastic equilibrium and the solution for the unloading of a centrally loaded disc to assess debonding was proposed by Hainsworth et al [31]. It was assumed that the fracture dissipated energy associated with debonding equals the total elastic energy stored in the flexed annular coating segment.

The energy release rate for the debonding is then given by [31],

$$
G_{\text {int }}=\frac{W_{d}}{\pi C_{R}^{2}}=\frac{2 E t^{3}\left(\delta_{m}-\delta_{r}\right)^{2}}{3 C_{R}^{4}}
$$

where, $\delta_{m}$ and $\delta_{r}$ are the maximum and residual depth, $C_{R}$ is the radius of the delamination.

However, this model dramatically overestimates the interfacial toughness. For example, for a $4 \mu \mathrm{m} \mathrm{TiN} / \mathrm{ZrN}$ multilayer on steel indented at $500 \mathrm{mN}$, the calculated $\mathrm{G}_{\mathrm{int}}=173$ to $716 \mathrm{~J} / \mathrm{m}^{2}$ from a debonding length of 5 to $7 \mu \mathrm{m}$ which is larger than results determined using other approaches for 
the same samples $\left(\sim 50 \mathrm{~J} / \mathrm{m}^{2}\right)$. It is very sensitive to the measured debonding length since the exponent of $C_{R}$ in Eq.(17) is 4. When applying this method to the ceramic coatings tested in this study, a value of around $20000 \mathrm{~J} / \mathrm{m}^{2}$ is calculated for $400 \mathrm{~nm} \mathrm{TiO}_{\mathrm{x}} \mathrm{N}_{\mathrm{y}}$ on glass which is clearly unrealistic [17]. Such overestimation was also demonstrated based on the use of a cohesive zone model embedded in a finite element simulation of the debonding during the indentation of strong films on ductile substrate [35]. The main reason for the overestimation is that significant stored energy remains in the coating due to bending and only a small fraction of the total stored energy was released during interfacial fracture.

An alternative energy based approach has been presented in [33-34] based on the modification of the indentation unloading curve when fracture takes place. When the coating is detached, the bent ligament of coating is still attached at the edge of the contact and acts like a spring pushing the indenter out of the impression during unloading. A linear unloading segment with a different slope to that in an undebonded sample is often observed. The work dissipated in this process is assumed to be given by the area between the experimental data and the extrapolation of the unloading curve from higher loads where no interfacial failure has taken place (as marked in Fig.21). This provides more reasonable results but it still overestimates the adhesion energy by more than 10 times for some coated systems (e.g. [34]).
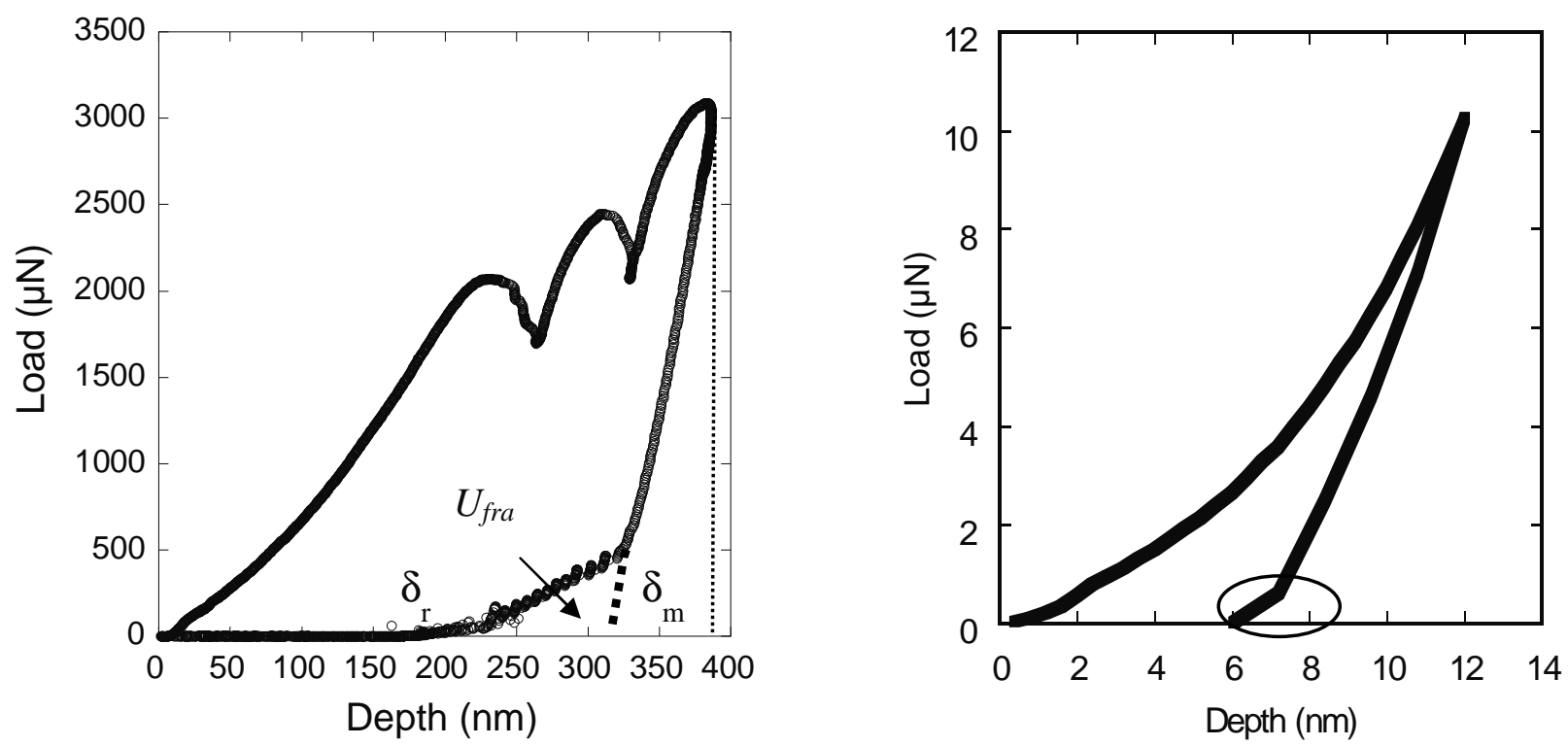

Fig.21. (a) Extra linear elastic recovery in the load-displacement curve observed during unloading for an $\mathrm{ITO} / \mathrm{Ag} / \mathrm{ZnO} / \mathrm{TiO}_{2}$ multilayer on commercial soda-lime glass (b) finite element simulation of delamination for water degraded $\mathrm{ZnO} / \mathrm{Ag} / \mathrm{ZnO} /$ glass.

Therefore, alternative approaches are still required for more accurate determination of interfacial toughness which will be discussed in the following. Recall that the delamination generated during unloading is caused by the tensile stress generated when elastic recovery is hindered by the presence of the plastic deformation zone beneath the indenter which is similar to the formation of lateral cracking around indentations in a bulk ceramic material. A method developed based on the expanding spherical cavity model to determine the toughness based on stress analysis of the lateral cracking process in bulk materials [36] gives

$$
K_{c}^{4}=\frac{P_{0} A_{0}^{2}}{\delta_{0}}(\cot \theta)^{\frac{2}{3}} \frac{H}{E} H^{3}
$$


where $P_{0}$ is threshold load for lateral cracking, $A_{0}$ and $\delta_{0}$ are dimensionless constants, $\left(A_{0}=3 / 4\right.$ and $\left.\delta_{0}=1200\right)$ and $\theta$ is the half-included angle for the indenter, the $H$ and $E$ are hardness and Young's modulus.

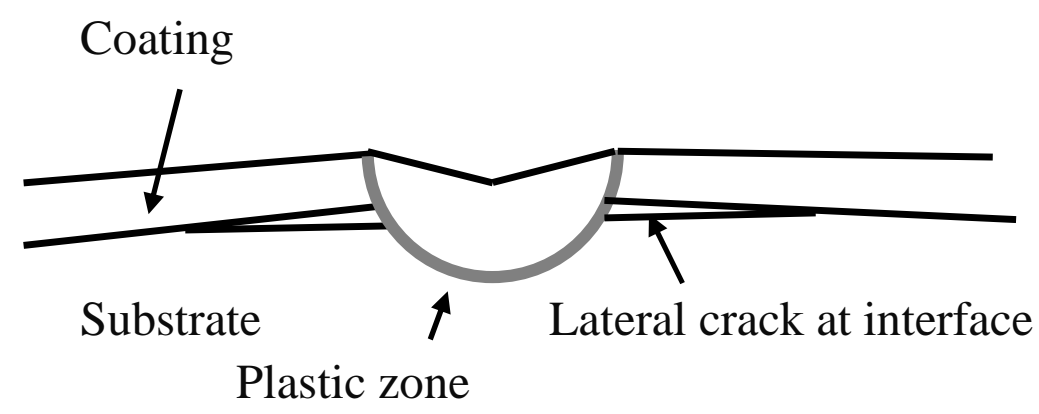

Fig.22. Schematic of lateral cracking at an interface during unloading.

Modifying this model by replacing the properties of a bulk material with those of the coated system, gives the interfacial toughness for a coated system provided that the interface is weaker than the coating or substrate. In this analysis the hardness and elastic modulus are composite parameters resulting from the contribution of the coating and substrate which can be directly measured or estimated based on the energy based model given in [37-38]. The critical load is not easy to directly measure due to the resolution limit of the microscopy techniques used to identify the extent of lateral fracture. As the lateral cracking normally occurs when the plastic deformation zone reaches the interface [16], the critical load can be estimated by the model presented in [39].

The advantage of applying this method to transparent coated glass samples is the fact that the lateral crack is visible in the light microscope since all coating materials and the substrate are transparent. In fact the reflectivity of the barely open segment of the crack near the crack tip is sufficiently high that accurate measurements of crack length are possible. Evidence of lateral cracking at the interface has been observed when the load exceeds $200 \mathrm{mN}$ (e.g. Fig.17b). It is clear that the lateral cracking is confined to the contact radius which suggests tensile stress induced delamination during unloading has occurred as well-documented in [16]. Therefore, Eq. (18) can be applied and we get an estimate of $\mathrm{G}_{\text {int }}$ of $1.9 \pm 0.4 \mathrm{~J} / \mathrm{m}^{2}$ for the Ag/ZnO interface in this study, which is in good agreement with the results determined by the other methods such as DCB [81] as shown in Table 1.

To validate this model, we have incorporated a cohesive zone model into finite element simulations of the indentation of coated systems. As documented in [40-42], the cohesive zone model allows the simulation of fracture initiation and propagation. The input parameters in the cohesive zone model are the interface strength and the energy release rate at the interface. For typical metal/ceramic coated systems, it shows that the calculated energy release rate by equation (18) is very close to the input value in the cohesive zone model (difference less than 10\%) (see more details in $[66,82]$ ).

\subsection{Adhesion assessment by scratch testing}

As discussed previously the scratch test produces a lot of different failure modes but only a few of these are associated with adhesion and it is essential that the stylus geometry, normal and tangential loads are accurately measured at the point of failure if quantitative analysis is to be attempted. In addition, the size and shape of the detached region needs to be accurately determined. 
One of the first energy based models was developed to determine the energy release rate of the interfacial crack, associated with the in-plane stresses stored in the coating ahead of the sliding stylus $[83,84]$.

$$
G=\frac{\sigma_{c}^{2} t}{2 E_{f}}
$$

Where $t$ is the coating thickness, $E_{f}$ is the Young's modulus of the coating,

The critical stress $\sigma_{c}$ is given by,

$$
\sigma_{c}=\sigma_{x}+\sigma_{r}
$$

Where $\sigma_{c}$ and $\sigma_{x}$ are the applied stress component in the sliding direction (x direction) and $\sigma_{r}$ is the residual stress[85].

$$
\sigma_{x}=\frac{P_{c}}{2 \pi a^{2}}\left[\left(1-2 v_{s}\right)-\mu \frac{3 \pi\left(4+v_{s}\right)}{8}\right]
$$

Where $P c$ is the critical load, $v_{s}$ is the Poisson's ratio of the substrate, $a$ is the contact radius, and $\mu$ is the friction coefficient between the coating and the indenter. In this model, no plastic deformation is accounted and it is assumed that the contact radius is overwhelming the coating thickness.

Burnett and Rickerby [86, 87] split up the driving forces for coating loss in three different components: (i) an elastic-plastic indentation stress; (ii) an internal stress component; (iii) tangential frictional stress. Considering the elastic-plastic deformation, Bull and Rickerby [88] suggested that,

$$
G=\frac{32 P_{c}^{2} t}{\pi^{2} d_{c}^{2} E_{f}}
$$

Where the $d_{c}$ is the scratch track width.

By taking account into the stress contribution to the friction coefficient, this model was further modified by Bull et al [89],

$$
G=\frac{P_{c}^{2} t v^{2} \mu_{c}^{2}}{2 E_{f} A^{2}}
$$

Where $A$ is the cross-sectional area of scratch track.

$$
A=R^{2} \arcsin \left(\frac{d_{c}}{2 R}\right)-\frac{d_{c}}{2}\left[R^{2}-\left(\frac{d_{c}}{2}\right)^{2}\right]^{1 / 2}
$$

This model assumes that the coating is loaded in pure compression without shear at the interface. With the increase of the coating thickness, the shear stress starts to play more important role. If the coating is delaminated and spalled simultaneously, the area that the friction force acts on is the cross-section of the coating instead of the scratch track, and thus, 
Considering the shear stress contribution and residual stress [2, 90-92], we get,

$G=\frac{\sigma_{r}^{2} t}{2 E_{f}}+\sum\left[\frac{\tau_{i j}^{2} t\left(1+v_{f}\right)^{2}\left(1-v_{f}\right)}{E_{f}}+\frac{\sigma_{i j}^{2} t\left(1+v_{f}\right)\left(1-v_{f}\right)}{2 E_{f}}\right]$

Where $\tau_{i j}^{2}$ and $\sigma_{i j}^{2}$ are the average shear and normal stress in the delaminated coating.

Thouless [22] developed a model to infer the critical load and hence calculate interfacial toughness based upon the geometry of the spalls. Upon the observation that the film delaminates and spalls within a sector of a disk region of length $L$ ahead of the indenter, Thouless (1998) proposed the following model to determine energy release rate $G$ based on stress analysis given by [93].

$$
G \approx \frac{P^{2}}{8 E(L \tan \beta+a)^{2} t}
$$

where $P$ is the load component at scratch direction, $E$ is the plane strain Young's modulus of the film, $2 a$ is the width of the scratch and $t$ is the film thickness, $\beta$ is the angle between the edge of coating spallation and the scratch direction.

In this model it is assumed that delamination occurs in response to the in-plane compressive stress imposed by the indenter. It is also assumed that the coating is so brittle that through thickness radial cracks are generated and they extend at an angle $\beta$ to the direction of scratch. The residual stress is not taken into account.

Provided that the interfacial toughness is much smaller than the substrate toughness, the delamination under uniform compression will be confined to the plane of interface. Interfacial crack extends with increasing load and it will buckle when the in-plane stress reaches a threshold. It will lead to spalling if the coating is brittle enough. Supposing the driving force for delamination equals critical load for buckling, Thouless derived the following equation for interfacial fracture energy, [22]

$$
G_{\text {int }}=0.35 \frac{E t^{5}}{L^{4}}\left(\frac{\tan \beta+2 a / L}{\tan \beta+a / L}\right)^{2}
$$

Where $L, a, \beta$ are the geometry parameters for the chip as depicted in Fig.23.

By considering the curved geometry instead of the initially assumed triangular shape and the residual stress, $\sigma_{\mathrm{r}}$, den Toonder et al modified the model giving ([24], [94]]

$$
G_{\mathrm{int}}=1.42 \frac{E t^{5}}{L^{4}}\left(\frac{\frac{a}{L}+\frac{\beta \pi}{2}}{\frac{a}{L}+\beta \pi}\right)^{2}+\frac{t(1-v) \sigma_{r}^{2}}{E}+\frac{3.36(1-v) t^{3} \sigma_{r}}{L^{2}}\left(\frac{\frac{a}{L}+\frac{\beta \pi}{2}}{\frac{a}{L}+\beta \pi}\right)
$$




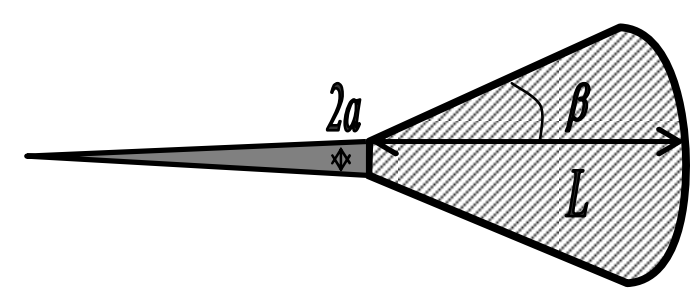

Fig.23 Schematic of a chipped area in analysis by Thouless [22].

This model is valid because the delaminated layer is often bounded by chevron radial cracks which point in the direction of sliding and are formed prior to interfacial failure. Another model based on the delamination occurring after the radial cracks leading to chipping ahead of the scratch was given by Malzbender et al [94].

$$
G_{\mathrm{int}}=0.158 \frac{E t^{5}}{L^{4}}(\sin \beta)^{2}+\frac{t \sigma_{r}^{2}}{2} \sqrt{\frac{1}{E \times E_{\mathrm{int}}}}
$$

Where the so-called elastic modulus of the interface, $E_{\text {int }}$ is given by[17],

$$
E_{\mathrm{int}}=\frac{1}{2}\left(\frac{1}{E_{f}}+\frac{1}{E_{s}}\right)
$$

Eq.(26) provides similar results for experiments carried out by indentation or scratch for sol-gel coatings on glass $\left([12],[53,54]\right.$,) Table 3 depicts the interfacial fracture toughness for $1 \mu \mathrm{m} \mathrm{CN}_{\mathrm{x}}$ coatings $(1 \mu \mathrm{m}$ thick) deposited on different samples determined by equation (26) which are sensible. The application of the method has yielded reasonable results for other coated systems elsewhere [95].

Table 3. Values of the interfacial fracture toughness for $\mathrm{CN}_{\mathrm{x}}$ coatings $(1 \mu \mathrm{m}$ thick) deposited on different samples determined by equation (26) [68].

\begin{tabular}{|l|l|}
\hline Coated system & $\mathrm{K}_{\text {int }}, \mathrm{MPa} \sqrt{\mathrm{m}}$ \\
\hline $\mathrm{CN}_{\mathrm{x}} / \mathrm{Si}(001)$ & 0.75 \\
\hline $\mathrm{CN}_{\mathrm{x}} / \mathrm{Al}_{2} \mathrm{O}_{3}$ & 0.68 \\
\hline $\mathrm{CN}_{\mathrm{x}} / 3 \mathrm{C} \mathrm{SiC}(001)$ & 0.40 \\
\hline $\mathrm{CN}_{\mathrm{x}} / \mathrm{SiC}(111)$ & 0.41 \\
\hline
\end{tabular}

However, different failure mechanisms can occur during scratch depending on the coated systems and the testing conditions. For example, a complete circular blister can be generated without the presence of the radial cracks as shown in Fig.23. When little or no plastic deformation or fracture occurs in the substrate (or coating) at the point of interfacial failure this is unconstrained and circular buckle failures starting from interfacial defects are likely to form. These are formed by the compressive stresses well ahead of the moving indenter and may be closed as the indenter slides over them and open up again once it has passed. Through-thickness cracking of the buckled coating may occur during this process leaving a pit. Alternatively a circular blister may be left as in Figure 24. As discussed in [16-18], for a soft metallic Ag layer sandwiched between $\mathrm{ZnO}$ coatings on glass the squeezed silver layer between the hard oxides coating increases the in-plane compressive stress at the interface which enhances the formation of a blister by buckling from a defect at the $\mathrm{Ag} / \mathrm{ZnO}$ interface. Further analysis by XPS, EDX confirms that it is $\mathrm{Ag} / \mathrm{ZnO}$ interface fails in the multilayer stack [18-19]. More details about experimental setting-up can be found in [96]. From equation (24), the contribution of the stress 
generated during the scratch goes to zero in case of the complete circular blister as $\beta=\pi$. However, in the absence of the scratch /indentation induced stresses, the residual stress is not sufficient to induce delamination. This implies that the model described in equation (26) cannot apply to the failure mechanism as shown in Fig.25. In the same way, the applicability of equation (25) is also in doubt.

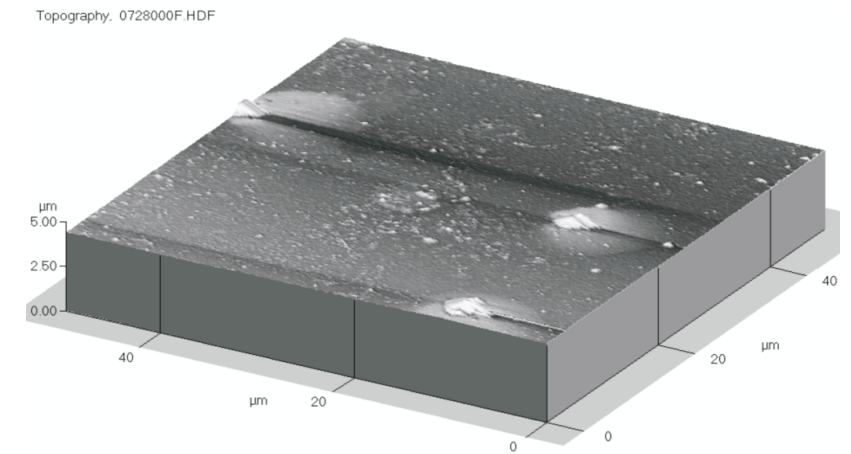

Fig.24. AFM image of scratch induced circular blisters at the $\mathrm{Ag} / \mathrm{ZnO}$ interface in the full solar control coating stack.

Blister formed head of the scratch and passed over

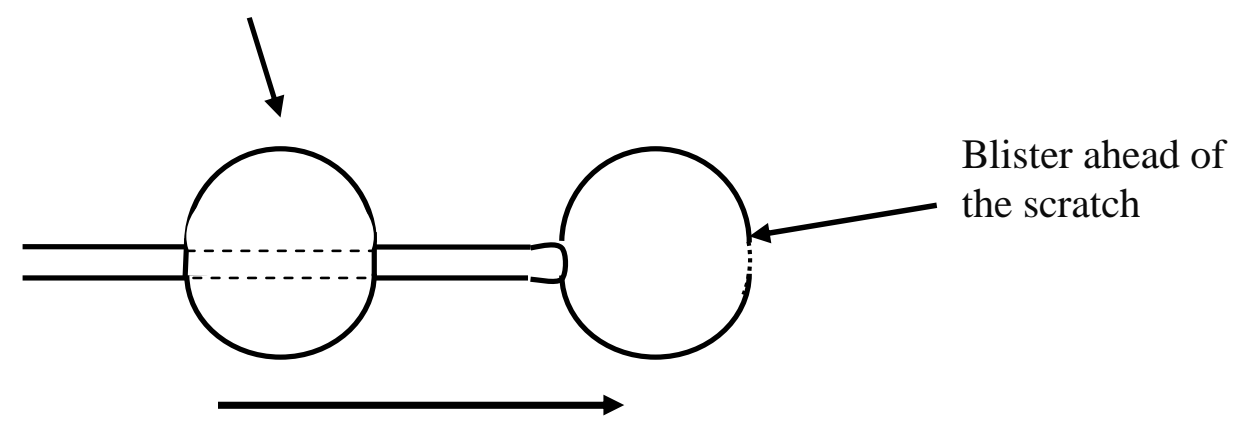

Scratch direction

Fig.25 Schematic of the relationship between the locations of circular blisters formed in this study and the scratch track that generated them [97].

Therefore, a more appropriate method is required. Recall the models described in Section 3.2 (i.e. Equations (10) and (11)) initially developed for indentation tests, which can be extended to scratch tests at constant load. This yields $G_{\text {int }}$ values of $0.8 \mathrm{~J} / \mathrm{m}^{2}$ and $2.1 \mathrm{~J} / \mathrm{m}^{2}$ by equations (10) and (11), respectively for the $\mathrm{Ag} / \mathrm{ZnO}$ interface investigated here. An estimation can also be made based on equation (1) which gives the overall stress (around $3 \mathrm{GPa}$ ) to cause this blister and $\mathrm{G}_{\text {int }}$ is around $2 \pm 0.4 \mathrm{~J} / \mathrm{m}^{2}$. Equation (10) mainly takes account of the energy dissipated by buckling. Thus, it can be expected that equation (11) is more reasonable as it considers the energetics of both buckling and crack propagation. The results determined by equation (11) agree well with the extended application of equation (5). It is the constant load testing condition and the unconstrained circular buckle failure mode that makes equations (10) and (11) more applicable than equations (25) and (26). This emphasises the fact that adhesion assessment by scratch tests is very sensitive to the test conditions. 


\subsection{Other considerations during adhesion assessment}

It can be seen that the elastic modulus of the coating appears in the all of the models to determine the interfacial toughness described here whereas the hardness of the coating is also involved in some cases. The approaches described to extract quantitative adhesion data are therefore most valid when there is little or no plastic deformation in the coating or substrate. It is essential to accurately determine the mechanical properties of the coatings if reliable adhesion data is to be extracted. When the coating becomes very thin, the nanoindentation/nanoscratch technique is one of the few techniques that can be used to extract this information but caution is required when interpreting the results as well documented in [98-103].

Another general observation is that the stress analysis-based methods for extraction of interface toughness contain geometric parameters such as coating thickness which are raised to high powers. The accuracy of the toughness data is thus critically dependent on the reliability of the thickness measurement and the uniformity of the coating. Energy-based analysis methods are less susceptible to this sort of error since measurement of crack area gives only a first order error. However, it can be difficult to identify what fraction of the total energy dissipation is accounted for by the observed fracture and careful correction for other dissipation sources (plasticity, microcracking, phase changes, heat, etc) must be undertaken if accurate data is to be obtained.

Nearly all tests assume that an accurate measure of crack geometry is possible and that the crack has a well-defined geometry. This is not always easy to achieve. For instance, as the coating thickness is reduced it is difficult to guarantee that the starter crack is at the coating/sustrate interface in a double cantilever beam test and the crack front does not remain linear as the crack propagates. In such circumstances it is necessary to repeat the testing many times to determine the variability of adhesion and exclude tests which deviate too much from the ideal geometry.

In all models the importance of residual stress cannot be overemphasised since the driving force for delamination will be a combination of residual stress and any applied stresses generated in the test. An accurate assessment of residual stress is therefore essential; whereas this is relatively straightforward for thick, crystalline coatings using x-ray diffraction or deflection methods (using the Stoney equation) it becomes a greater challenge as the coating thickness decreases. Many oxide coatings deposited on glass are poorly crystalline and cannot be assessed by x-ray diffraction. To get reliable data from coatings of a few tens on nanometres thick on glass in such circumstances requires depositing coatings on very thin glass substrates $(<100 \mu \mathrm{m})$ or polishing thicker substrates to this thickness to achieve measurable curvature. In addition, if the calculation is based on chipping, it is recommended to measure the actual fracture area instead of assuming the circular plate. The circular plate is partially separated due to the pre-existing radial crack or the pre-dominant severe plastic deformation at an edge. Examination of the surface profile can help to identify the mechanism.

\section{Selection of adhesion tests}

For the most reliable adhesion test it is necessary to minimise plastic deformation in the coating/substrate system and maximise the stresses responsible for delamination. When selecting an appropriate adhesion test there are therefore a number of key questions which need to be answered: 
1) What are the bulk properties of the coating and substrate? In nearly all adhesion tests stresses need to be transferred to the interface through the coating or substrate and the substrate must be rigid enough to withstand these stresses without failure during the adhesion test. It is usually assumed that the interface strength is lower than the bulk cohesive strength of the coating or substrate but this is not always true. Brittle substrates, such as glass, are not usually suitable for bending tests but can be used in double cantilever tests where the bending stresses are usually lower. However, sometimes a precrack is intentionally induced in the brittle substrate and it may divert to the interface to cause delamiantion.

2) What is the coating thickness? The defects in coatings which lead to interfacial failure tend to have sizes comparable to the coating thickness. This provides a practical limit to the thickness of coating which can be reliably assessed. For instance, in pull-off tests with an epoxy adhesive (strength $50 \mathrm{MPa}$ ) it is not usually possible to assess coatings of less than $10 \mu \mathrm{m}$ thickness since the defects are too small to propagate at the maximum stress before the adhesive fails. The adhesion of thinner coatings may also be compromised by glue penetration to the interface. Buckling failures are most common when the coating is thin enough to bend so adhesion tests based on generating buckles or blisters (bulge tests, indentation tests) are most useful for thin coatings $(<5 \mu \mathrm{m})$. For thicker coatings with higher bending stiffness then shear cracking in the coating is observed which may not propagate along the interface if the substrate is brittle or the adhesion is good.

3) How good is the adhesion? For a range of coating and substrate materials, the values of $\mathrm{G}_{\text {int }}$ recorded typically vary between 1 and $300 \mathrm{~J} / \mathrm{m}^{2}$ with interfacial toughness varying from $1-15 \mathrm{MPam}^{1 / 2}$. Nearly all tests are suitable when the adhesion is poor $\left(\mathrm{G}_{\mathrm{int}}<5 \mathrm{~J} / \mathrm{m}^{2}\right)$ but as the adhesion strength increases the choice of tests becomes increasingly limited, particularly is the coating is thin and brittle. For $\mathrm{G}_{\text {int }}$ greater than $50 \mathrm{~J} / \mathrm{m}^{2}$ it is usually necessary to use indentation or scratch methods to generate interfacial failure; due to the frictional (shear) term in the stresses during scratching the failure will tend to occur at lower applied loads with less damage to the substrate. However, this may change the mode mixity in the test. For highly adherent coatings, the combination of overstressed layer and scratch may be required to generate interfacial failure but quantitative analysis is difficult due to excessive plastic deformation in the coating/substrate system. In addition, the cross section indentation tests by a wedge indenter can be a good option.

4) Can the residual stress be controlled? To use the stressed overlayer method it is necessary to be able to deposit coatings with controlled stress onto the test coating with better adhesion than between the tested interface. For highly stressed coatings spontaneous delamination often occurs and this gives a very reliable interfacial toughness. Increasing the residual stress in a coating until such failures occur can be a very good way of assessing adhesion.

5) What causes in-service adhesion failure? Since there is no ideal adhesion test it is often better to choose a test which closely matches the conditions which will cause in service failure. For instance, for microelectronics metallisation coatings which undergo a lot of thermal cycles and multiple depositions during processing, the stressed overlayer (or controlled residual stress) methods are most appropriate whereas for coated architectural glass where delamination around transit scratches is an issue then an indentation or scratch test is most appropriate.

For the thin oxide coatings on glass tested in this study $(<400 \mathrm{~nm}$ thick) the adhesion is sufficiently good that only the most highly stressed ITO films will spontaneously delaminate. The brittle glass substrate makes four point bend testing impossible but some success has been achieved with double cantilever beam tests (opened with a wedge) where the substrate thickness is minimised to minimise bending stresses and substrate fracture. In cases where the adhesion 
has been compromised by environmental exposure (e.g. $\mathrm{SnO}_{2}$ coatings after water exposure ([8], [104]) it is possible to use indentation tests to generate detachment. However, the only reliable measure of delamination of all the different oxide coatings on glass was obtained using the scratch test. Introducing a softer metal layer into the coating stack (e.g. Ag in a solar control coating) reduces interfacial toughness and makes adhesion testing easier using both double cantilever beam and indentation tests.

\section{Summary}

Adhesion is a critical parameter in most coating applications and many tests have been developed to assess it. It shed the light on the analysis of failure mechanisms at specific test conditions and coated systems before choosing the models to assess the adhesion.

When adhesion is poor, most tests can be used to generate reliable interfacial toughness data, although some calibration is necessary if results are to be compared for different tests or for different analysis methods using the same test. As adhesion gets better, the choice of tests is reduced.

Reducing the coating thickness also adds complications since the stored elastic energy in the coating which drives delamination is reduced and it is very difficult to generate stable starter cracks with well-defined geometry into the interface.

To achieved fully quantified adhesion testing for thin films when interfacial toughness is high $\left(>8 \mathrm{MPam}^{0.5}\right)$ may be almost impossible in many cases. However, in such circumstances performance is usually dominated by failure of the coating or substrate and the need for a precise value for interfacial adhesion is secondary. Thus, the vary fact that interfacial failure does not occur in an indentation or scratch test may be sufficient to guarantee coating adhesion unless very high bending or shear stresses are applied to the coating/substrate system.

\section{Acknowledgements}

The first author (J.C.) thanks Prof. E. Barthela and Dr. D. Dalmas in CNRS/Saint-Gobain, Prof. R. Smith, Dr. S. Kenny and Dr. I. Gheewala in Loughborough University, Dr. Z.S. Lin in TIPC, Chinese Academy of Sciences, Dr. P. Bristow in Cambridge University for providing me with details of their group publications. Richard Nay and Lance Kuhn from Hysitron Inc. are acknowledged for sharing the AFM images of the nanoscratch induced delamination in a multilayered polymer low- $k$ coating. In addition, J.C. would also like to acknowledge Prof. D. L. Bader in QMUL for his kind advice on the outline of the manuscript. This work was funded, in part, by the EPSRC Multiscale modelling programme.

[1] Mittal KL. Adhesion measurement of thin films. Electroc p. Sci. Technol. 1976;3.

[2] Volinsky AA, Moody NR, Gerberich WW. Interfacial toughness measurements for thin films on substrates. Acta Materialia 2002;50:441.

[3] Lipkin DM, Clarke DR, Evans AG. Effect of interfacial carbon on adhesion and toughness of gold-sapphire interfaces. Acta Materialia 1998;46:4835.

[4] Busscher HJ, Vanpelt AWJ, Dejong HP, Arends J. 2 Methods to Calculate Surface FreeEnergies from Contact-Angle Measurements. Journal of Dental Research 1983;62:453.

[5] Busscher HJ, Vanpelt AWJ, Dejong HP, Arends J. Effect of Spreading Pressure on Surface Free-Energy Determinations by Means of Contact-Angle Measurements. Journal of Colloid and Interface Science 1983;95:23. 
[6] Busscher HJ, Vanpelt AWJ. The Possibility of Deriving Solid-Surface Free-Energies from Contact-Angle Measurements with One Liquid. Journal of Materials Science Letters $1987 ; 6: 815$.

[7] Furuya A, Hosoi, N., Ohshita, Y., . Evaluation of Cu adhesive energy on barrier metals by means of contact-angle measurement. J. Appl. Phys. 1995;78:4.

[8] Lin ZS, Bristowe PD. Microscopic characteristics of the $\operatorname{Ag}(111) / \mathrm{ZnO}(0001)$ interface present in optical coatings. Physical Review B 2007;75.

[9] Lin ZS, Bristowe PD. A density functional study of the effect of hydrogen on the strength of an epitaxial Ag/ZnO interface. Journal of Applied Physics 2007;102.

[10] Lawn BR. Fracture of Brittle Solids. Cambridge: Cambridge University Press, 1993.

[11] Warren PD, Hills DA, Roberts SG. Surface Flaw Distributions in Brittle Materials and Hertzian Fracture. Journal of Materials Research 1994;9:3194.

[12] Malzbender J, de With G, den Toonder JMJ. Elastic modulus, indentation pressure and fracture toughness of hybrid coatings on glass. Thin Solid Films 2000;366:139.

[13] Thouless MD. Cracking and Delamination of Coatings. Journal of Vacuum Science \& Technology a-Vacuum Surfaces and Films 1991;9:2510.

[14] Hutchinson JW, Suo Z. Mixed mode cracking in layered materials. Adv. Appl. Mech. 1992;29:63.

[15] Evans AG, Hutchinson JW. On the Mechanics of Delamination and Spalling in Compressed Films. International Journal of Solids and Structures 1984;20:455.

[16] Chiang SS, Marshall DB, Lawn BR, Evans AG. A simple method for adhesion measurements. In: Evans P, editor. Surfaces and interfaces in ceramic and ceramic metal systems. New York: Plenum, 1981. p.603.

[17] Hutchinson JW, Suo Z. Mixed-Mode Cracking in Layered Materials. Advances in Applied Mechanics, Vol 29 1992;29:63.

[18] Dundurs J. Edge-bonded dissimilar orthogonal elastic wedges. Journal of Applied Mechanics 1969;36.

[19] Bogy DB. On the problem of edge-bonded elastic quarter-planes loaded at the boundary,. Int. J. Solids Struct. 1970;6.

[20] Schmauder S. Theory of the Elastic Interface Crack. Fortschrittsberichte der Deutschen Keramischen Gesellschaft: Werkstoffe, Verfahren, Anwendung, Beiheft zu CFI (Ceramic Forum International) 21987.

[21] Hull TR, Colligon JS, Hill AE. Measurement of Thin-Film Adhesion. Vacuum 1987;37:327.

[22] Thouless MD. An analysis of spalling in the microscratch test. Engineering Fracture Mechanics 1998;61:75.

[23] Blees MH, Winkelman GB, Balkenende AR, den Toonder JMJ. The effect of friction on scratch adhesion testing: application to a sol-gel coating on polypropylene. Thin Solid Films 2000;359:1.

[24] den Toonder J, Malzbender H, de With G, Balkenende R. Fracture toughness and adhesion energy of sol-gel coatings on glass. Journal of Materials Research 2002;17:224.

[25] Venkataraman S, Kohlstedt DL, Gerberich WW. Continuous microscratch measurements of the practical and true works of adhesion for metal/ceramic systems. Journal of Materials Research 1996;11:3133.

[26] Richard CS, Beranger G, Lu J, Flavenot JF, Gregoire T. Four-point bending tests of thermally produced WC-Co coatings. Surface \& Coatings Technology 1996;78:284.

[27] Hughey MP, Morris DJ, Cook RF, Bozeman SP, Kelly BL, Chakravarty SLN, Harkens

DP, Stearns LC. Four-point bend adhesion measurements of copper and permalloy systems.

Engineering Fracture Mechanics 2004;71:245.

[28] Bagchi A, Lucas GE, Suo Z, Evans AG. A New Procedure for Measuring the Decohesion Energy for Thin Ductile Films on Substrates. Journal of Materials Research 1994;9:1734.

[29] Bagchi A, Evans AG. Measurements of the debond energy for thin metallization lines on dielectrics. Thin Solid Films 1996b;286:203. 
[30] Bagchi A, Evans AG. A new procedure for measuring the decohesion energy for thin ductile films on substrates - Reply. Journal of Materials Research 1996a;11:2112.

[31] Jindal PC, Quinto DT, Wolfe GJ. Adhesion Measurements of Chemically VaporDeposited and Physically Vapor-Deposited Hard Coatings on Wc-Co Substrates. Thin Solid Films 1987; 154:361.

[32] Marshall DB, Evans AG. Measurement of Adherence of Residually Stressed Thin-Films by Indentation .1. Mechanics of Interface Delamination. Journal of Applied Physics 1984;56:2632.

[33] Chiang SS, Marshall DB, Evans AG. A simple method for adhesion measurements. In: Evans P, editor. Surfaces and interfaces in ceramic and ceramic metal systems. New York: Plenum, 1981. p.603.

[34] Gupta V, Yuan J, Pronin A. Recent Developments in the Laser Spallation Technique to Measure the Interface Strength and Its Relationship to Interface Toughness with Applications to Metal-Ceramic, Ceramic-Ceramic and Ceramic Polymer Interfaces. Journal of Adhesion Science and Technology 1994;8:713.

[35] Zhou M, Zhang YK, Cai L. Adhesion measurement of thin films by a modified laser spallation technique: theoretical analysis and experimental investigation. Applied Physics aMaterials Science \& Processing 2002;74:475.

[36] Dalmas D, Barthel E, Vandembroucq D. Crack front pinning by design in planar heterogeneous interfaces. Journal of the Mechanics and Physics of Solids 2009;57:446. [37] Barthel E, Kerjan O, Nael P, Nadaud N. Asymmetric silver to oxide adhesion in multilayers deposited on glass by sputtering. Thin Solid Films 2005;473:272.

[38] Jacobsson R. Measurement of Adhesion of Thin-Films. Thin Solid Films 1976;34:191.

[39] Katz G. Adhesion of Copper-Films to Aluminum-Oxide Using a Spinel Structure Interface. Thin Solid Films 1976;33:99.

[40] Leterrier Y, Sutter P, Manson JAE. Thermodynamic and micromechanical approaches to the adhesion between polyethylene terephthalate and silicon oxide. Journal of Adhesion 1999;69:13.

[41] Charalambides PG, Lund J, Evans AG, McMeeking RM. A test specimen for determining the fracture resistarim of bimaterial interfaces. Journal of Applied MechanicsTransactions of the Asme 1989;56:77.

[42] Harry E, Rouzaud A, Ignat M, Juliet P. Mechanical properties of W and W(C) thin films: Young's modulus, fracture toughness and adhesion. Thin Solid Films 1998;332:195.

[43] Nie PL, Lv,H.P., Zhou,T., Cai, X., Chu, P.K. Interfacial adhesion measurement of a ceramic coating on metal substrate. Journal of Coatings Technology and Research 2009.

[44] Hohfelder R, Luo, H., Vlassak, J., Chidsey, C., Nix, W. MRS Symp. Proc. , vol. 436. Boston,MA, USA, 1997. p.115.

[45] Small MK, Nix WD. Analysis of the Accuracy of the Bulge Test in Determining the Mechanical-Properties of Thin-Films. Journal of Materials Research 1992;7:1553.

[46] Ostojic P, McPherson R. Determining the Critical Strain-Energy Release Rate of PlasmaSprayed Coatings Using a Double-Cantilever-Beam Technique. Journal of the American Ceramic Society 1988;71:891.

[47] Geng X. Failure Mechanisms of Weak Adhesion Optical Coatings Under Sliding Contact, Ph.D Thesis. Pierre et Marie Curie University, 2008.

[48] Charalambides PG, Lund, J., Evans, A.G., Mcmeeking, R.M. . A test specimen for determining the fracture resistance of

bimaterial interfaces. J Appl Mech 1989;111:77.

[49] Gupta V, Argon AS, Cornie JA, Parks DM. Measurement of Interface Strength by LaserPulse-Induced Spallation. Materials Science and Engineering a-Structural Materials Properties Microstructure and Processing 1990;126:105.

[50] Matoy K, Detzel T, Muller M, Motz C, Dehm G. Interface fracture properties of thin films studied by using the micro-cantilever deflection technique. Surface \& Coatings

Technology 2009;204:878. 
[51] Tada H, Paris, P.C., Irwin, G.R. The Stress Analysis of Cracks Hand Book. ASME Pr, New York 2000.

[52] Bull SJ. Interfaces and adhesion, . In: Gissler W, Jehn HA, editors. Advanced techniques for Surface Engineering. ECSC, EEC, EAEC, Brussels and Luxembourg., 1992. p.31.

[53] Malzbender J, de With G. Scratch testing of hybrid coatings on float glass. Surf. Coat. Technol. 2001;135:202.

[54] Malzbender J, de With G. Analysis of scratch testing of organic-inorganic coatings on glass. Thin Solid Films 2001;386:68.

[55] Malzbender J, de With G. Modeling of the fracture of a coating under sliding indentation. Wear 2000;239:21.

[56] Malzbender J, de With G. Sliding indentation, friction and fracture of a hybrid coating on glass. Wear 1999;236:355.

[57] Bull SJ, Berasetegui EG. An overview of the potential of quantitative coating adhesion measurement by scratch. Tribology International 2006;39:99.

[58] Malzbender J, de With G. Energy dissipation, fracture toughness and the indentation load-displacement curve of coated materials. Surface \& Coatings Technology 2000;135:60.

[59] Chen J, Bull, S.J. Assessment of the adhesion of ceramic coatings,. Advances in Science and Technology 2006;45:1299.

[60] Li XD, Diao DF, Bhushan B. Fracture mechanisms of thin amorphous carbon films in nanoindentation. Acta Materialia 1997;45:4453.

[61] He MY, Evans AG, Hutchinson JW. Crack Deflection at an Interface between Dissimilar Elastic-Materials - Role of Residual-Stresses. International Journal of Solids and Structures 1994;31:3443.

[62] Yeap KB, Zeng KY, Chi DZ. Determining the interfacial toughness of low-k films on Si substrate by wedge indentation: Further studies. Acta Materialia 2008;56:977.

[63] Yeap KB, Zeng KY, Jiang HY, Shen L, Chi DZ. Determining interfacial properties of submicron low-k films on Si substrate by using wedge indentation technique. Journal of Applied Physics 2007;101.

[64] Ritter J, Lardner T, Rosenfeld L, Lin M. Measurement of adhesion of thin polymer coatings by indentation. J. Appl. Phys. 1989;66:3626.

[65] Mencik J. Mechanics of components with treated coated surface. Dordrecht, The Netherlands: Kluwer, 1996.

[66] Chen J, Bull SJ. Finite element analysis of contact induced adhesion failure in multilayer coatings with weak interfaces. Thin Solid Films 2009;517:3704.

[67] Rosenfeld LG, Ritter JE, Lardner TJ, Lin MR. Use of the Microindentation Technique for Determining Interfacial Fracture Energy. Journal of Applied Physics 1990;67:3291.

[68] Fernandez-Palacio J, Arce-Garcia I, Bull SJ. Indentation response of fullerene-like CNx. Tribology International 2004;37:929.

[69] Suresh S, Shih CF, Morrone A, Odowd NP. Mixed-Mode Fracture-Toughness of Ceramic Materials. Journal of the American Ceramic Society 1990;73:1257.

[70] Li WZ, Siegmund T. An analysis of the indentation test to determine the interface toughness in a weakly bonded thin film coating substrate system. Acta Materialia 2004;52:2989.

[71] Marshall DB, Evans, A. G. . Measurement of Adherence of Residually Stressed ThinFilms by Indentation: 1. Mechanics of Interface Delamination . Journal of Applied Physics 1984 562632.

[72] Etienne-Calas S, Duri A, Etienne P. Fracture study of organic-inorganic coatings using nanoindentation technique. Journal of Non-Crystalline Solids 2004;344:60.

[73] DeBoer MP, Gerberich WW. Microwedge indentation of the thin film fine line.1. Mechanics. Acta Materialia 1996;44:3169.

[74] DeBoer MP, Gerberich WW. Microwedge indentation of the thin film fine line .2. Experiment. Acta Materialia 1996;44:3177. 
[75] Vlassak JJ, Drory MD, Nix WD. A simple technique for measuring the adhesion of brittle films to ductile substrates with application to diamond-coated titanium. Journal of Materials Research 1997;12:1900.

[76] Kriese MD, Gerberich WW, Moody NR. Quantitative adhesion measures of multilayer films: Part I. Indentation mechanics. Journal of Materials Research 1999;14:3007.

[77] Demarecaux P, Lesage J, Chicot D, Mesmacque G. An Examination of the Validity of the Interface Indentation Test - Application to Thermal Sprayed Coatings. Vide-Science Technique Et Applications 1994:524.

[78] Chicot D, Demarecaux P, Lesage J. Measurement of the apparent interface toughness by interfacial indentation tests. Revue De Metallurgie-Cahiers D Informations Techniques 1996;93:245.

[79] Chicot D, Demarecaux P, Lesage J. Apparent interface toughness of substrate and coating couples from indentation tests. Thin Solid Films 1996;283:151.

[80] Sanchez JM, El-Mansy S, Sun B, Scherban T, Fang N, Pantuso D, Ford W, Elizalde MR, Martinez-Esnaola JM, Martin-Meizoso A, Gil-Sevillano J, Fuentes M, Maiz J. Cross-sectional nanoindentation: A new technique for thin film interfacial adhesion characterization. Acta Materialia 1999;47:4405.

[81] Barthela E, Kerjana O, Naela P, Nadaudb N. Asymmetric silver to oxide adhesion in multilayers deposited on glass by sputtering.

Thin Solid Films 2005;473:272.

[82] Chen J, Bull SJ. Indentation fracture and toughness assessment for thin optical coatings on glass. Journal of Physics D-Applied Physics 2007;40:5401.

[83] Laugier MT. An Energy Approach to the Adhesion of Coating Using the Scratch Test. Thin Solid Films 1984;117.

[84] Laugier MT. Adhesion of TiC and TiN Coatings Prepared by Chemical Vapour Deposition on WC-Co-Based Cemented Carbides. J. Mater. Sci., 1986;21.

[85] Hamilton GM, Goodman, L. E. . The Stress Field Created by a Circular Sliding Contact. ASME J. Appl. Mech. 1966;33.

[86] Burnett PJ, Rickerby DS. The Relationship between Hardness and Scratch Adhesion. Thin Solid Films 1987;154:403.

[87] Burnett PJ, Rickerby DS. The Scratch Adhesion Test - an Elastic-Plastic Indentation Analysis. Thin Solid Films 1988;157:233.

[88] Bull SJ, Richkerby, D.S. New developments in the modelling of the hardness and scratch adhesion of thin films. Tribology International 1990;42:149.

[89] Bull SJ, Rickerby DS, Matthews A, Leyland A, Pace AR, Valli J. The Use of Scratch Adhesion Testing for the Determination of Interfacial Adhesion - the Importance of Frictional Drag. Surface \& Coatings Technology 1988;36:503.

[90] Venkataraman S, Kohlstedt DL, Gerberich WW. Microscratch Analysis of the Work of Adhesion for Pt Thin-Films on Nio. Journal of Materials Research 1992;7:1126.

[91] Venkataraman SK, Nelson JC, Hsieh AJ, Kohlstedt DL, Gerberich WW. Continuous Microscratch Measurements of Thin-Film Adhesion Strengths. Journal of Adhesion Science and Technology 1993;7:1279.

[92] Moody NR, Hwang RQ, Angelo JE, Venkataraman S, Gerberich WW. Residual stress effects on the fracture of tantalum nitride films. Interfacial Engineering for Optimized Properties 1997;458:453.

[93] Hutchinson JW, Suo Z. Mixed-Mode Cracking in Layered Materials. Advances in Applied Mechanics, Vol 29, vol. 29. 1992. p.63.

[94] Malzbender J, de With G. A model to determine the interfacial fracture toughness for chipped coatings. Surface \& Coatings Technology 2002;154:21.

[95] Garcia IA. Mechanical properties of fullerene-like CNx, Ph.D thesis. University of Newcastle Upon Tyne, 2002. 
[96] Belde KJ, Bull SJ. Intentional polymer particle contamination and the simulation of adhesion failure due to transit scratches in ultra-thin solar control coatings on glass. Journal of Adhesion Science and Technology 2008;22:121.

[97] Chen J, Lin ZS, Bull SJ, Phillips CL, Bristowe PD. Experimental and modelling techniques for assessing the adhesion of very thin coatings on glass. Journal of Physics DApplied Physics 2009;42.

[98] ISO 14577-4, 2007.

[99] Chen J, Bull SJ. On the factors affecting the critical indenter penetration for measurement of coating hardness. Vacuum 2009;83:911.

[100] King RB. Elastic Analysis of Some Punch Problems for a Layered Medium. International Journal of Solids and Structures 1987;23:1657.

[101] Gao H, Chiu, C.H., Lee, J. Elastic Contact Versus Indentation Modeling of MultiLayered Materials. International Journal of Solids and Structures 1992;29:2471.

[102] Mencik J, Munz,D., Quandt,E., Weppelmann, E.R. Determination of elastic modulus of thin layers using nanoindentation. J. Mater. Res. 1997;12:2475.

[103] Chen J, Bull SJ. On the relationship between plastic zone radius and maximum depth during nanoindentation. Surface \& Coatings Technology 2006;201:4289.

[104] Belde K, Bull S.J. . Chemomechanical effects in optical coating systems. Thin Solid Films 2006;515:859. 